Portland State University

PDXScholar

1984

\title{
You don't have to have a high school education to work here : an ethnography of a chainstore
}

Caroline Yvonne Princehouse

Portland State University

Follow this and additional works at: https://pdxscholar.library.pdx.edu/open_access_etds

Part of the Social and Cultural Anthropology Commons Let us know how access to this document benefits you.

\section{Recommended Citation}

Princehouse, Caroline Yvonne, "You don't have to have a high school education to work here : an ethnography of a chainstore" (1984). Dissertations and Theses. Paper 3584.

https://doi.org/10.15760/etd.5470

This Thesis is brought to you for free and open access. It has been accepted for inclusion in Dissertations and Theses by an authorized administrator of PDXScholar. Please contact us if we can make this document more accessible: pdxscholar@pdx.edu. 
AN ABSTRACT DF THE THESIS OF Caraline Yvonne Princehouse for the Master of Arts in Anthropology presented May 2, 1984.

Title: You Don"t Have to Have a High School Education to Work Heres An Ethnography of a Chainstore.

APPROVED BY MEMBERS DF THE THESIS COMMITTEE:

Dani el J. Scheane, Chairman

Marc R. Feldesman

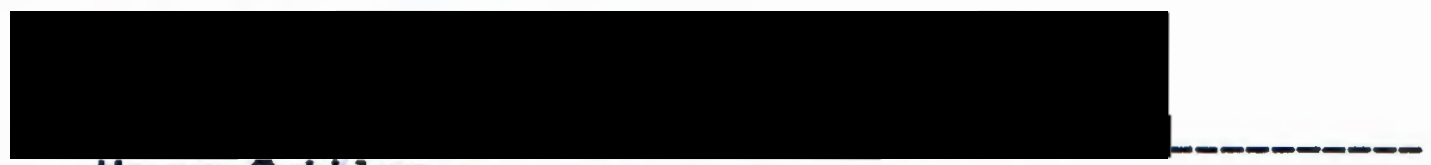

Wayne suteles

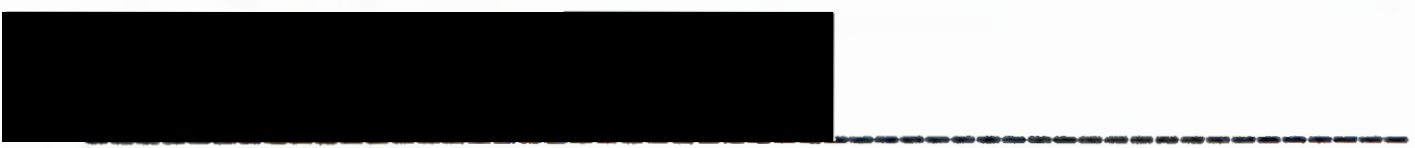

Leonard D. Cain

Thi a ethnography is a study of the cultural scene at one store of a chain of twenty-eight retail "discount departwent stores"--the Bi Mart Company, a subsidiary of the Pay in Save Corporation. It is an exercise of an 
ethnographic mothod developed by Jamos spradley that is used to uncover and describe the cultural gramar of acquired knowledge which Bi Mart employees use to define and interpret their situation and to generate and understand their work. The method is based on the assumption that culture is best learned and best described (as wuch as possible) from the "native" point of view.

As athnographer, I applied the DRS Itrategies set forth in Spradley' two companion works---The Ethnggeaghic Interview and Pacticipant gbgervation. I becamo a student of nembers in the Bi Mart cultural scene, starting as an initiate, and undergoing a fore of encul turation allowing m. to discover and interpret life in the scene in the same ways members do. Casual conversations and participant observation awong the people made it possible to formulate hunches and hypotheses which became the bases for formal interviewe with informants. I discovered cultural patterns and oventually waw the data fit into the wider explanatory picture which I was able to confirm and deseribe in this thasis. The description provides the information which a stranger mould need to know to act appropriately in the Bi Mart ecene.

In short, nembers in this scene build up a repertoire of rough cast wisdons, practices and beliefs which allow them to carry out their work and cope 
effectively in an everyday way. They call thi a knowledge "common sense" and they aseort "it is not laarned in school". It is learned on-the-job---as "know how" is transoitted from the experienced pereons to the inexperieneed ones. Individuale areend a highly etructured hierarchy of situations during the course of their Bi Mart training. They accumulate and placo a high premiue on "experience" they acquire, which they aseret is valuable and useful for "gotting ahead" and "staying on top of things*.

Other cultural ereantial includes

- fidality to a kind of habitual minimalism and a predisposition to anke a virtue of neceseity.

-an application and understanding of a "basic" way to conduct business in a Bi Mart stora.

- wilingnese of individuale to move around in order to move ahead.

-a highly wocial lifestyle which revolves around an inage of thewelver as a comonity or "fanily"-on which relations are imudiate, concrete, congenial, supportive and 1 oyal.

Although wy formal rewerch entailed a thorough examination of only one Bi Mart store, I believe the deneription applies to all other Bi Mart otoros. A replication of the rewearch would mont likely cluster the 
28 stores together as unique frow others in many ways. Bi Mart people emphasize a need to maintain themselves as distinct. Fictive kinship and the other culturally developed traditions and sensibilities are their on creations and they will remain so as long as employers continue to believe in them. 
you don't have to have a HIGH SCHOOL EDUCATION TO WORK HERE:

AN ETHMOGRAPHY OF A CHAINSTORE

$$
\text { by }
$$

CAROLINE YUONNE PRINEEHOUSE

A thesis submitted in partial fulfillment of the requirements for the degree of

\author{
MASTER OF ARTS \\ in
}

ANTHROPOLOGY

Portland State University

1984 
TO THE OFFICE OF GRADUATE STUDIES AND RESEARCH:

The members of the Committee approve the thesis of Caroline Yvonne Princehouse presented May 2, 1984.

Daniel J. Scheans, Chairman

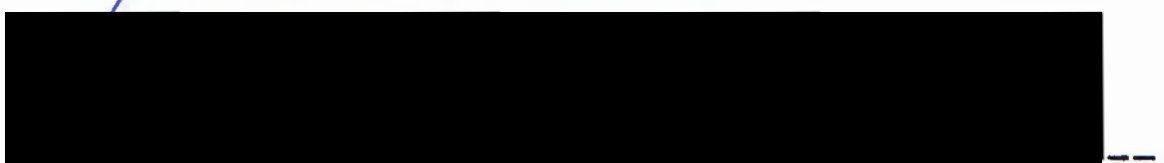

Marc R. Feldesman

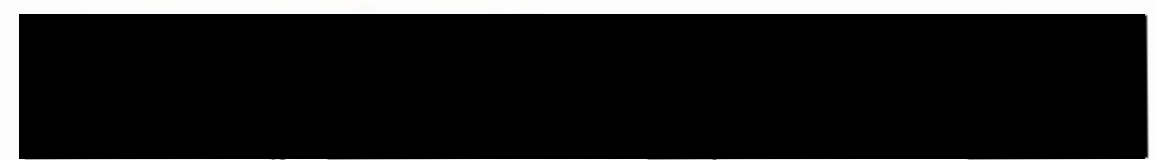

Wayne Sut'tles

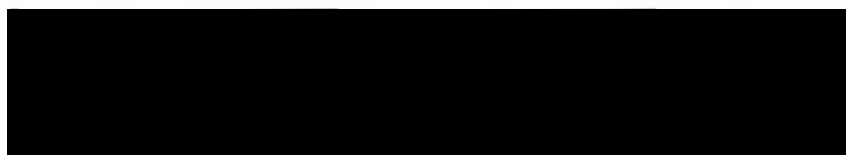

Leonard D. Cain

APFKOVED:

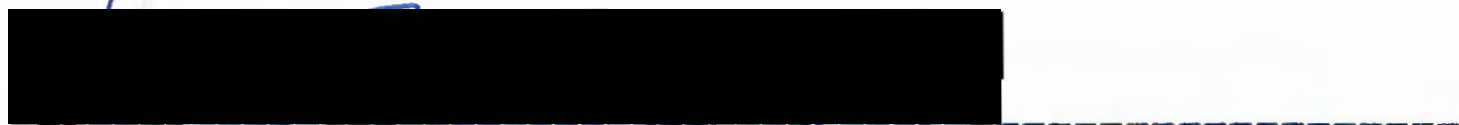

Marc R. Feldesman, Head, Department of Anthropology

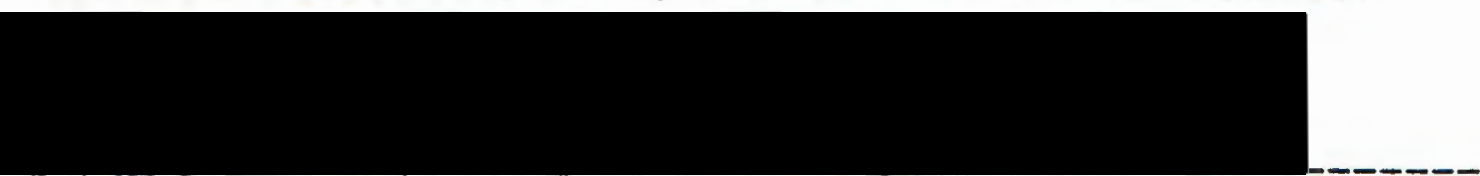

Stanley E. Rauch, Dean of Graduate Studies and Research 
TABLE OF CONTENTS

PAGE

LIST OF TABLES . . . . . . . . . . . . . . . . . . vi vi

LIST OF FIGURES . . . . . . . . . . . . . . . . . . Vii

CHAPTER

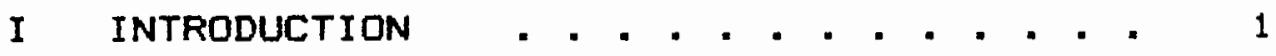

Theoretical Orientation . . . . . 5

Research Method .......... 6

Purpose ............... 10

Prologue . . . . . . . . . . 10

I I THE START: GRAND OPENING. . . . . . . . . 14

Getting Ready . . . . . . . . . 16

Grand Opening Day . . . . . . . . . . 18

I I THE SCENE: "INSIDE THE STORE" . . . . . . 30

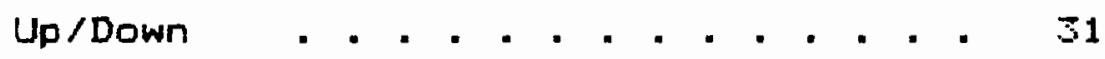

Front/Back. . . . . . . . . . . . . 34

The "Floor"
The "Backroom"
The "Breakroom"
The "Office"

IV THE PEOPLE . . . . . . . . . . . . . . .43

The Informal Network: The Bi Mart Family. 45

Insiders/Outsiders

Affect and Sentiment 


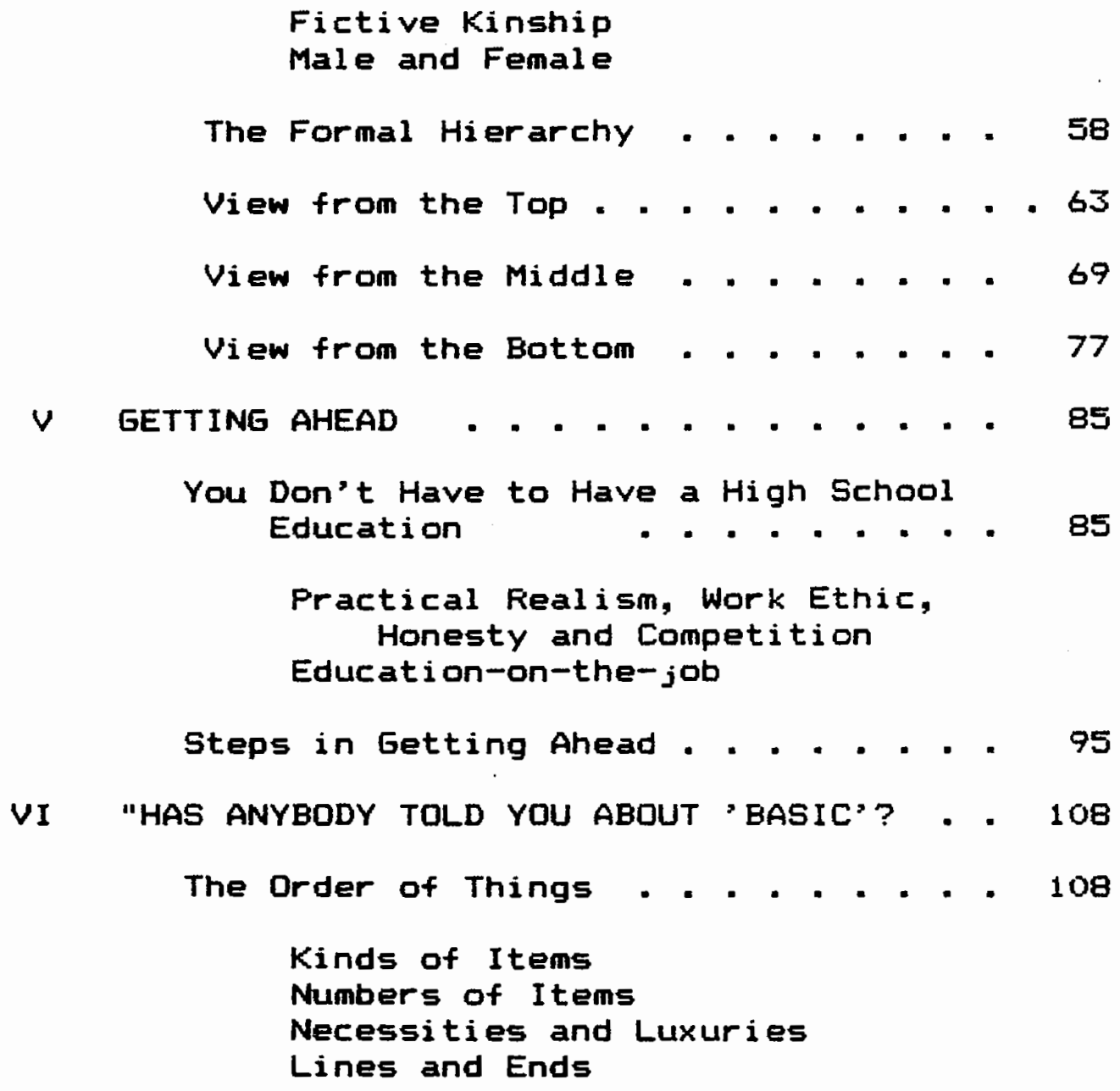


REFERENCES

APPENDIX A

APPENDIX B 


\section{LIST OF TABLES}

TABLE

PAGE

I Structural Representation of Store Divisions 30

I I Taxonomy of Store Space. . . . . . . . 33

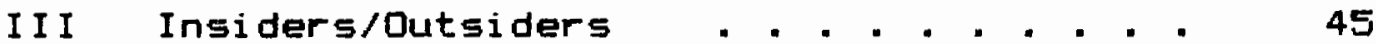

IV Division of Labor by Sex . . . . . . . 57

V Financial Process... . . . . . . . . 90

VI Kinds of Items . . . . . . . . . . . . 110

VII Basic Investment and Inventory . . . . . 113

VIII Componential Analysis of Drugs and Fhoto-

Sound Departments . . . . . . . . 116

IX Componential Analysis of Minolta Line of

Pocket Cameras 


\section{LIST OF FIGURES}

F IGURE

PAGE

1. "Grand Dpening". . . . . . . . . . . . 13

2. From outside the store, into the lobby, down the main aisle, and through the checkstands 25

3. Into the departments. . . . . . . . . 26

4. Department managers and clerks at their department desks . . . . . . . . . . .

5. Into the office. . . . . . . . . . . 28

6. In back areas... . . . . . . . . . 29

7. Formal organization . . . . . . . . . 60

8. Structure of the steps in getting ahead. 96

9. Steps in getting ahead . . . . . 100-106

10. Analysis of pocket cameras . . . . . . 118

11. Map of store "floor" . . . . fold-out pocket

12. Map of upstairs warehouse . . . . . . . . 145

13. Schematic of hardware department.fold-out pocket

14. Detailed schematic of four-foot section. 146

15. Stock control card . . . . . . . . . 147

16. "What's Happening" . . . . . . . . . . . . . 148 


\section{CHAPTEF I}

\section{INTRODUCTION}

Ethnography has come home to become a fundamental tool for understanding ourselves and the multicultural societies of the modern world (Spradley 1980). It is no longer relegated to exotic cultures in far off places. However, ethnographic traditions developed in alleged "primitive isolates" are useful for research in American urban settings as 1) a framework in which to order the structural segments of a complex society and 2) an approach to understanding the behaviors of interacting segments of the population (Clinton 1977). In multicultural societies, large aggregates of people live in close proximity and still maintain somewhat different cultures, usually called subcultures. And within these groups there are cultural scenes known to some but not to others. I have chosen to study the cultural scene at one store of a chain of 28 retail "discount department stores," the Bi Mart Company, a subsidiary of the Fay " $n$ Save Corporation, as a ready-made unit in the study of work in one of many of the occupational subcultures which 
comprise the blend of diverse institutions constituting American society today.

When anthropologists study small non-Western societies they find people participating in a single web of life. In complex societies, such as our own, the number of cultural perspectives for any situation increases radically (Spradley 1980). The Bi Mart cultural scene is not merely one small, interesting group of people who work together; it is part of the human species in a particular way. of course, economics imposes certain limitations and constraints on organization, but productive forces operate only within the context of definite social relations (Holzberg 1981).

Stores, in general, are places of employment for milions of men and women. At one level, a store operates as a merchandising institution to do the business of distributing goods required by society at 1arge. At another level, a store is a place, a common ground, where people come together to play out various statuses and roles in complex social interaction. To outsiders, or non-employees, Bi Mart is simply a place to shop. To insiders, or employees, Bi Mart is much more; it is a world of varied cultural meanings that must be learned in order to carry out the work and cope with 
difficulties. In this paper I want to show how complex this cultural knowledge is in contrast to the casual impression held by outsiders.

Much of the behavior of workers at Bi Mart, as in every human society, is organized on the basis of a shared symbolic world wherein categories are used to sort and classify experience and rules are established for appropriate behavior. In order to function, each individual acquires a cognitive map which enables her or him to interpret behaviors and events observed. Individuals learn to evaluate each experience in a way that is at least partially shared. At Bi Mart, these shared values become the basis for such things as setting up a department, taking-making-giving orders, getting along with others, asking for a promotion, and becoming a store manager. Participants use plans to organize their behavior in the pursuit of goals. My focus in this case study of a workplace as a cultural scene will be on the search for, and description of, the culturally meaningful symbols, attitudes, and values that integrate the individuals as they participate in this scene.

My interest in doing ethnography at Bi Mart began when I became employed by the Bi Mart Company in the fall of 1979. I prepared for, and participated in, the "Grand Opening" of two stores in Salem, Oregon. For the past 
four years I have spent approximately 40 hours every week. in these two stores. My position as a pharmacist offered a ready-made opportunity for participant-observation. Participation in the capacity of a medical professional was a sidelight to the main store function and chain-ofcommand--in technical language, "staff" as opposed to "I ine"---thus permitting me to assume a research role of interested bystander. At the same time, my insider status made it necessary, as well as easy, for me to gain both rapport and information. Observation was facilitated because of the location of the pharmacy in the front corner of the store, an elevated area separated from but overlooking the "floor" through windows of counter height: it is next to the stairs leading up to the office and the "breakroom" directly overhead. Here I was able to pay attention to much of what was happening in the store without making those observed uncomfortably aware of my presence among them. Although my formal research entailed a thorough examination of only one of the Bi Mart stores in which I am employed, I believe that much of the description and analysis is applicable to all other Bi Mart stores, and a replication of the research would most likely cluster the 28 stores together as distinet from others in many ways. 
THEORETICAL ORIENTATION

Ethnography is the primary field of endeavor in cultural anthropology. The ethnographic method I used is based on the assumption that culture is best learned and best described (as much as possible) from the "native" point of view. One essential aspect of ethnography concerns the meaning of things, actions, and events to the people the anthropologist studies and seeks to understand. Some of these meanings are directly expressed in language; many are taken for granted and communicated only indirectly through words and actions. But in every society people make constant use of complex meaning systems to organize their culture.

Ethnography always implies a theory of culture (Spradley 1979). Culture, as defined by James Spradley, and used in this research, refers to "the acquired knowledge that people use to interpret experience and generate social behavior." By restricting the definition of culture to shared knowledge I did not eliminate an interest in objects, behaviors, customs, or emotions. I merely shifted emphasis from these phenomena to their meanings. I saw artifacts and objects but looked beyond them to find out what meanings people assigned them. I 
observed behaviors but also inquired into the meanings of these actions. I recorded emotional states but went beyond them to discover the meanings of these feelings. Cultural description followed from the significant aspects and organization of these meanings which individuals acquire in order to anticipate events and behave in a manner which other members consider appropriate in this cultural scene.

\section{RESEARCH METHOD}

The best way to learn ethnography is by doing it (Spradley 1980). "Doing ethnography" means learning from people. In order to grasp the perspective of the persons studied and to discover the hidden principles of another way of 1 ife, the researcher becomes a student of the culture, starting with a conscious attitude of an initiate and undergoing a form of enculturation which allows the anthropologist to define and interpret life in the scene in the same way members do. The two major tasks---discovery and description---involve learning a new language of native terms, observing and participating in work activities and ceremonies, taking field notes to record what people do and say in the course of ordinary activities, recording life histories to discover how individuals experience their culture, recording folktales 
and genealogies, conducting ethnographic interviews with key informants, carefully analyzing their responses to questions, and integrating the data from multiple informants. At Bi Mart, I made use of all these activities as I attempted to glean information from all sources available.

In general, the method was a search for questions in the field situation. Casual conversations and participant observation among the people made it possible to formulate hunches and hypotheses which later became the bases for the formal ethnographic interviews which I began in January, 1981 . As I studied their cultural knowledge, patterns began to emerge relating the details and their significances; gradually, over the next three years, the data fit into the wider explanatory picture which I have been able to confirm and describe in this thesis.

In particular, I selected two companion works of James Spradley to guide my ethnographic research. Farticipant observation focuses on how to make inferences from what people do, and what they make and use. The Ethnograghic Interview focuses on how to make inferences from what people say. Concentrating on mastery of these two field techniques, Spradley designed twelve major 
tasks to guide the investigator from the starting point of selecting a social situation to the goal of writing the ethnography. The Developmental Research Sequence (DRS) set forth the strategies which I followed item by item. Farticipant observation involves:

1) locating a social situation

2) doing participant observation

3) making an ethnographic record

4) making descriptive observations

5) making a domain analysis

6) making focused observations

7) making a taxonomic analysis

8) making selected observations

9) making a componential analysis

10) discovering cultural themes

11) taking a cultural inventory

12) writing an ethnography

The ethnographic interview involves:

1) locating an informant

2) interviewing an informant

3) making an ethnographic record

4) asking descriptive questions

5) analyzing an ethnographic interview

6) making a domain analysis

7) asking structural questions 
8) making a taxonomic analysis

9) asking contrast questions

10) making a componential analysis

11) discovering cultural themes

12) writing an ethnography

Each of these larger tasks is broken down into many smaller ones for completion before moving from step 1 to step 2, from step 2 to step 3 , and so on.

In short, a large corpus of 1 inguistic and other data offered by informants (names of individuals have been changed to maintain confidentiality) in their own words and in their own ways examined for terms and categories relevant to them. Both similarities and differences among the terms and categories were discovered via a triadic sorting task in which informants were asked "which two out of three are most alike?" and "which one is different?" Inclusive relationships among the discovered terms and categories were revealed by domain analyses and taxonomic analyses. Contrast relationships and dimensions of meaning surfaced in the componential analyses which foll owed.

From these accountings of the data, I was able to discover the significant and distinguishing features which nembers in this cultural scene use to organize 
themselves and their work. Thus, I came to describe the cultural grammar which Bi Mart employees use to define their situation and understand their experience.

\section{PURPOSE}

The primary aims of the research were

1) to grasp the "native" view of life at Bi Mart---to realize their vision of the world, to decipher their symbolic codes, and to discover the cultural rules employees use to maintain their culture

2) to describe, as explicitly as possible, what the knowledge thus attained demonstrates about this particular scene in its complexities, and beyond that about social life in general, and

3) to enrich the body of ethnographic works---by applying a method of analysis using terms generic to the scene being studied because the human beings in this scene are valuable in their own right.

\section{PROLOGUE}

The department store as an institution and modern consumerism arose simultaneously, the one complementing the other. In the early $1800^{\prime} 5$ big scale offerings of large repertories of goods, with fixed prices and prearranged into departments under one roof, were able to 
attract large numbers of shoppers. This created an atmosphere of convenience and display which allowed for more familiarity in a world of things. While going to the store everyday, men and women came to express themsel ves as consumers.

After the mid-nineteenth century, cooperative owners of department stores in Britain found it profitable to open branches, or similar stores in different locations. Thus, they introduced the idea of "chainstores."

Twentieth century Americans became pacesetters for retail practices. Grocery chains came to cater to the needs of the working class whose numbers made up for what its individual members lacked in wealth. During the 1930 's, "super" markets began to display packaged food items on open racks, and customers not only compared prices marked on the items but also served themselves. Price reductions reconciled the public to the loss of personal service.

In the 1950 "s, "discount" houses became important; supermarket methods, such as buying in bulk or quantity from manufacturers at discount rates, advertising regulariy, daily if possible, selling at lower mark-ups and increasing turnover were applied to the whole sphere 
of consumer products. Cheap goods and unaccustomed luxuries from abroad came within the reach of ordinary people. While shopping according to the dictates of necessity, people learned to buy things they didn"t need. Today the strain of selection in shopping has come to require shrewd assessment and deliberation. Promotional campaigns and newspaper and television advertising for "the latest" things educate the public for more successful participation as modern consumers. The institutionalization of sales sustains shopping as a perpetual social drama, particularly as the concept of obsolescence quickens the tempo of change of impressive lifestyle and status-conferring accouterments. In stores, confrontation with the variety of irresistibly attractive goods intensifies the desire to possess them. The presence and style of those who can afford to buy, set the standards and raise the expectations of those who can't (yet), but show promise. Dreaming of it in the present, both the businessmen, with visions of moneymaking, and the consumers, with aspirations of moneysaving, savor the future moment when the actual purchase takes place. 


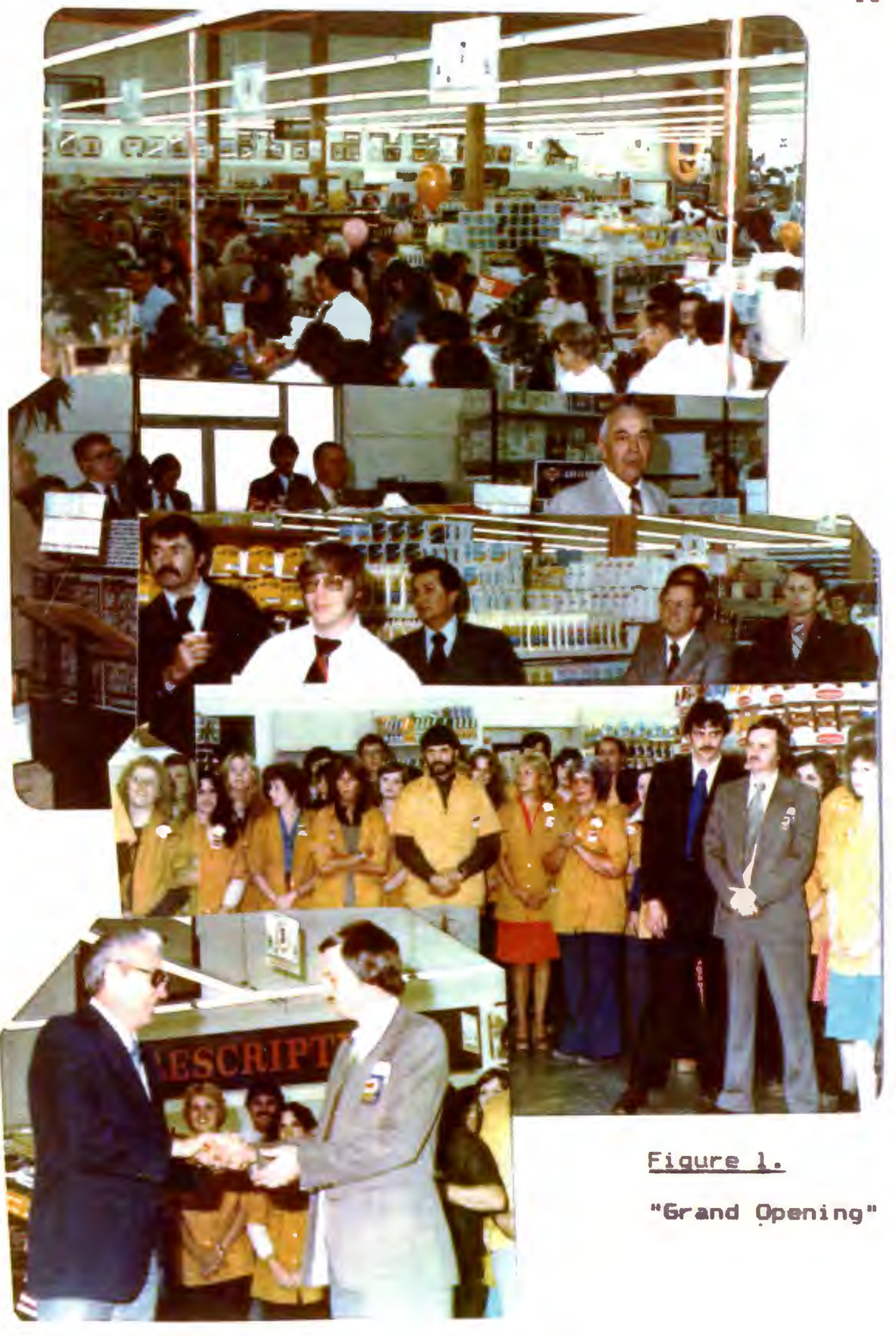


CHAPTER II

THE START

"GRAND DPENING"

It is a hazy, warm Thursday in early October, 1979, slightly before 10 A.M.. Multicolored flags are gently waving high about the expansive parking lot where cars are beginning to fill the 400 spaces. Shoppers park and get out of their cars. Some are carrying folded newspaper tabloids, others are holding small slips of paper, perhaps shopping lists. A line of people chatting with one another forms in front of an unobtrusive entrance door on the right side of the massive cement block structure. This building has no windows and could be mistaken for a warehouse were it not for the large orange sign, plainly lettered "BI MART" across its front.

In contrast to its ordinary exterior, the interior of the store is lively with the flourish of an extraordinary event. "Grand Opening" is a special day, happy but hectic, during which introductory bargains are offered, and employees, old and new, high and low, are allied and bonded in ceremony. A formal rite is in 
process: the "higher ups" are bestowing authority upon Greg Jahnke and his two assistants as the new store managers. Gary Garrison, Bi Mart general merchandiser, as master of ceremony, introduces visiting dignitaries including Mr. Vigeland, the company president, two of the three district managers, several merchandisers and buyers, the heads of personnel, advertising and construction and others from Eugene. There are five visiting Bi Mart store managers. As the elders of the culture, all these gentlemen and one woman reaffirm the past and provide an identification with the traditions of the company. At most times illusory to employees, today these company executives appear in person and are charismatic; dressed in business suits, they exude confidence and success. Their presence offers psychological backing to subordinates as they set out to engage in the tasks of this day of reckoning. They offer good wishes and proffer expressions of hope for another profitable enterprise.

As this group breaks up, the head men shake hands or slap each other on the back. Many congratulate those newly promoted to the management team, who appear somewhat nervous, but are revelling in the excitement of their new charge. Department managers, clerks, and 
cashiers, all wearing freshly laundered, orange smocks, stand attentively around the store managers; some imitate them. All participants wear nanetags to label them to outsiders as to position and area of responsibility. Many know each other from previous working relationships in other Bi Mart stores in other towns. At least they are familiar by reputation via friends of friends in the chain. Even some outsiders---suppliers and salespeople who appreciate or seek business relationships---offer their services for the day free of charge. Everyone seems to be enjoying being a part of something bigger than themsel ves.

For the previous month, employees have worked col lectively moving merchandise into the store, onto the floor, up on the shelves so customers can move it through the checkstands and out the exit door. Getting tired together in sharing this comanon effort they have become close, "like a family."

\section{GETTING READY}

The Bi Mart Company wanted to open three stores in Salem to economize on advertising. It was decided to buy property and build the first store at South Salem, and, shortly thereafter, open another store at North Salem. Interest rates were so high that the construction of an 
East Salem store had to be postponed. Property for the two stores was found on the outskirts at the opposite ends of the sprawling community where real estate could be acquired cheaply, and construction began in June. 1979.

In early September, when the upper and middle management teams took over, the store wasn't quite ready. First these store eaployees cleaned. Next they unloaded the shelving components off the trailers of two semi trucks. Chalk lines were drawn on the gray cement floor; it was predetermined how many "runs" of shelving would go across. An informant reports:

You gotta line' en up straight. In a store this deep they gotta be straight. Aisles are the same length throughout the store. Shelving runs along both sides of them.

They assembled the gondolas out of four-foot sections. Areas were left for the bulk stacks which are wider than the normal aisles. According to a store manager:

Stack' 'em high, and watch 'em buy! Bulk stacks are, literally, large stacks of merchandise without shelving. Like bags of fertilizer in hardware, cases of oil in automotive, boxes of kleenex in drugs. Cut the boxes, set them in the bulk stack.

The second week they stocked the merchandise in the departments, starting in the back corner of the store with hardware, then moving forward into housewares and 
photo-sound, across the front of the store to drugs, and back to sporting goods, automotive, and toys. Receiving schedules were correlated and synchronized by the buyers from company headquarters in Eugene "so that twenty-eight trucks weren't sent out the first day."

By the third week, additional workers arrived at the scene and each department was "on its own." Receiving people "trucked freight" from the back room onto the floor. Each department manager and the department clerks checked in their items, priced them, and put them onto the shelves. Extra persons were hired to operate a portable bailer which was wheeled into the middle of the store. As told by an informant:

Everybody was throwing empty cardboard boxes there. Each 150 pound bail was trucked back to fill the empty Bi Mart trailers, recycled and sold. What else can you do with tons and tons of empty boxes?

The night before Grand Opening, the store was ready; all the merchandise was on the shelves and neatly "faced." Brightly colored balloons were tied to the gondol as.

\section{GRAND OPENING DAY}

Grand Dpening has become established by custom, as eaployees rally together in successive performances of the continuing pageant of Bi Mart life. On this day, 
according to prescribed form, employees act out their parts and mount the spectacle to affirm their sense of obligation and loyalty to the company. They share with the public the celebration of their continuing business success. Prices are slashed.

Anticipation is in the air. Finally, all employees move to their respective places in the store. At $10 \mathrm{~A} . \mathrm{M}$. Greg Jahnke unlocks the front door. People flood into the lobby and are greeted over an intercom with the traditional message, "Good morning Bi Mart shoppers. Welcome to South Salem Bi Mart." It is explained that there is a temporary suspension of the usual $\$ 2$ lifetime membership fee. This was established in 1955 to provide Capital investment for the first Bi Mart store. When Bi Mart began in Yakima, Washington cooperative membership permitted sales of name-brand items below "fair trade" prices of manufacturers; when the state laws were overturned Bi Mart kept the membership rule to avoid reimbursements to all previous joiners.

Today, membership gives customers a sense of belonging. It has several advantages for the firm. It permits selective direct mailings of advertisements. Knowing where nembers 1 ive helps to indicate where new stores are feasible by spotting concentrations of 
existing members through $z$ ip codes. It reduces the number of bad checks, because identification for check cashing is by presentation of a numbered Bi Mart card. Finally, it is credited with discouraging shoplifting. After entering the store, customers procure shopping carts, orient themselves, and scurry off to search for the desired items while they last. Twenty 19inch color televisions are sold before noon. Clerks take names and phone numbers, issue "sorry slips," and contact the company distribution center (D.C.) and other Bi Mart stores to transfer the requested sets into the store as soon as possible. One hundred televisions are sold during this first day according to the photo-sound manager, "fifty more probably could have been."

$$
\text { Receiving clerks "hustle freight," pushing }
$$
handtrucks of merchandise through the throngs of people toward the departments and pleading, "Excuse me please. Can I get through?" Items are scooped off the top as they shuffle past eager shoppers. More people wait for them at locations designated by eye-catching signs and empty spaces. These are a few of the only spaces noticeable amidst the wall-to-wall people.

"It's a real barn burner!" according to Greg Jahnke. Crowds jam the store but, happily, everyone is caught up in the festive mood. Lines are twenty to forty 
persons in length at, the seventeen checkstands but customers are willing to wait to pay the hottest prices Bi Mart has ever offered. One woman told a cashier she waited in 1 ine for an hour "but it was worth it." Another cashier reported 200 patrons at her register befare her break at noon. At intervals, store managers make X-readings (subtotals), take change to the tills, and draw currency out as it piles up. They carry the money upstairs and jokingly say, "Here's more--our allowance" as they hand it to two bookkeepers who, behind closed doors, count it and prepare the night deposit. They say "the more dollar signs they see, the happier they get."

Excitement continues throughout the day. First impression is reminiscent of the pandemonium of the last minute rush at Christmastime, or, as described by an informant---"everyone running around crazy." But careful observation reveals an underlying integration of habits of thought, sentiment and action among store workers. Commication is possible because a common 1 anguage is understood. "Sackers to the front, please," and from the back of the store a girl rushes up to the checkstands to take her place beside a cashier; she quickly packs the purchased items into brown paper bags for the customer to 
carry out. "Shopping carts to the lobby please," and two men rush outside the store to gather up the empty metal carts and return them to the store entrance. From a chaotic parking lot they radio for assistance to direct traffic that is backing up onto the street as 600 cars vie for 400 spots. Back inside the store, managers give orders in voices raised to offset the noise of the hustle and bustle; they are acknowledged by nods from subordinates with countenances flushed with exertion.

Interaction is heightened among employees during a Bi Mart Grand Opening. Workers form new friendships which remain important throughout their Bi Mart careers. A mesh of mutual obligations and support forges them into the unified identity that they are "all in it together" to serve the shoppers. The market transaction is minimized, and consociation is maximized.

Customer membership and a "no frills" sensibility incorporated into the public service credo distinguish Bi Mart from its competitors. A store manager says:

This is not a fancy store. There is no carpeting, just a plain concrete floor. There's no wild colors on the walls, just plain white for light reflection.

The vast open floor is not partitioned so that 1 ight from fixtures hanging from the ceiling is not obstructed. Gridiron plans with numbered aisles intersecting at right 
angles, though monotonous, bespeak practicality and economy in form and function. Regular newspaper advertising ( Su $T$ W) disseminates this sentiment along with the Bi Mart economic of "quality goods at low prices." According to the company president:

Most department stores use a markup of $40 \%$ over wholesale cost; chainstores add around $34 \%$; fellow discounters operate on a $28 \%$ markup: Bi Mart marks up about $20 \%$.

Large numbers of shoppers were attracted to this Grand Dpening. The store closes at 9 P.M. with a customer count of 13,500. A total of 685 memberships have been sold for \$1357 (\$8 short). Sales are over a hundred thousand, almost a hundred and fifty thousand dollars. It has been the biggest opening day for any store in the chain; even with high inflation, some time will pass before this record is broken.

A party in a rented hall provides the inevitable climax to this long, special day. The beer is free for a11; employees celebrate and let off steam. Grand Dpening has been a day for dramatization and exaggeration of many occupational activities to follow. This day, and everyday at Bi Mart, workers enact roles, accomplish tasks, and acquire statuses. What unites them? $A$ job to make money and pay the bills; a place to find friends and enjoy social interaction; an opportunity to prove 
themselves valuable as they climb a corporate ladder to success; and whether they realize it or not, ultimately, this involves an attempt to give meaning to their lives and to the lives of others. 


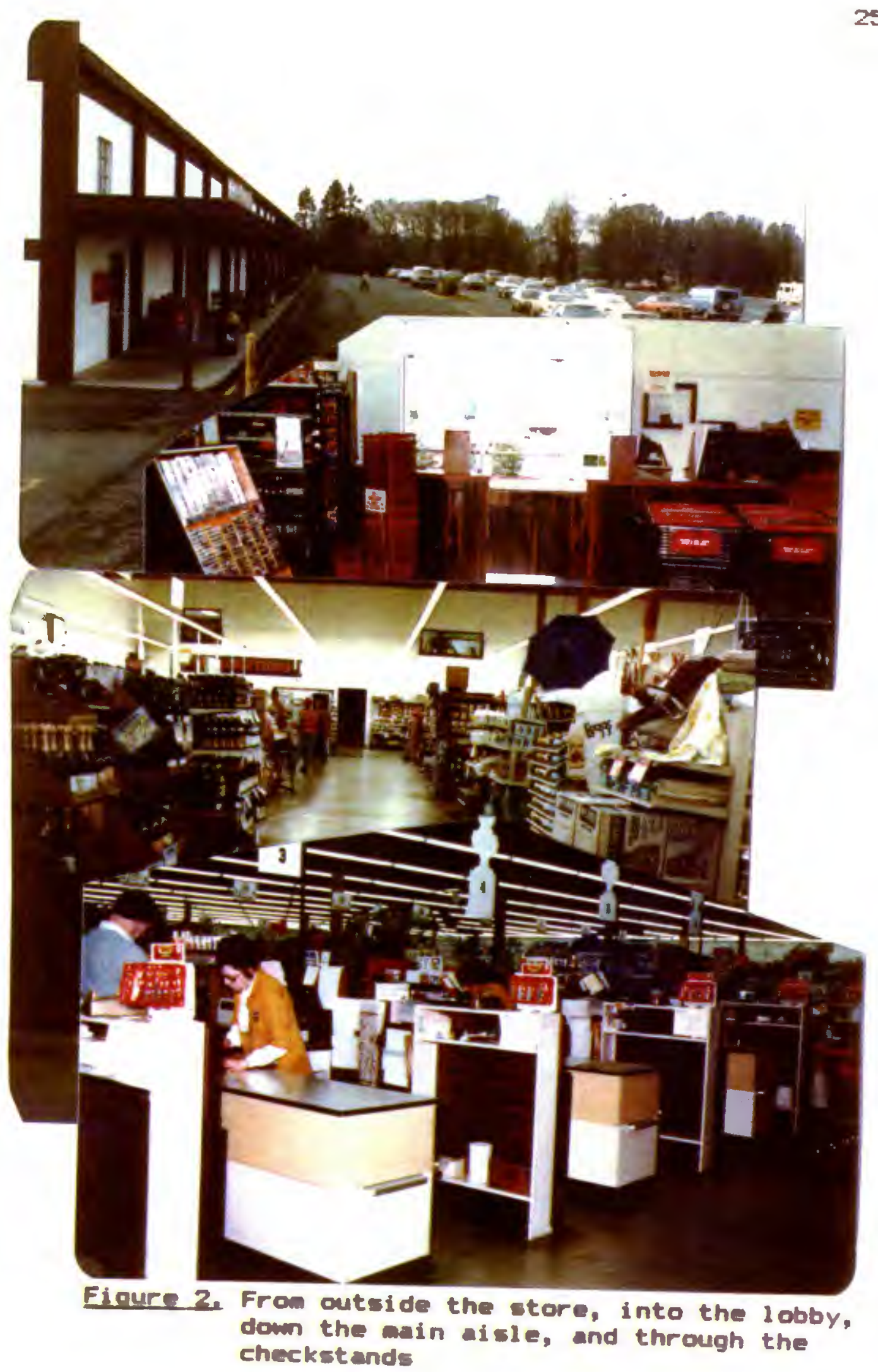




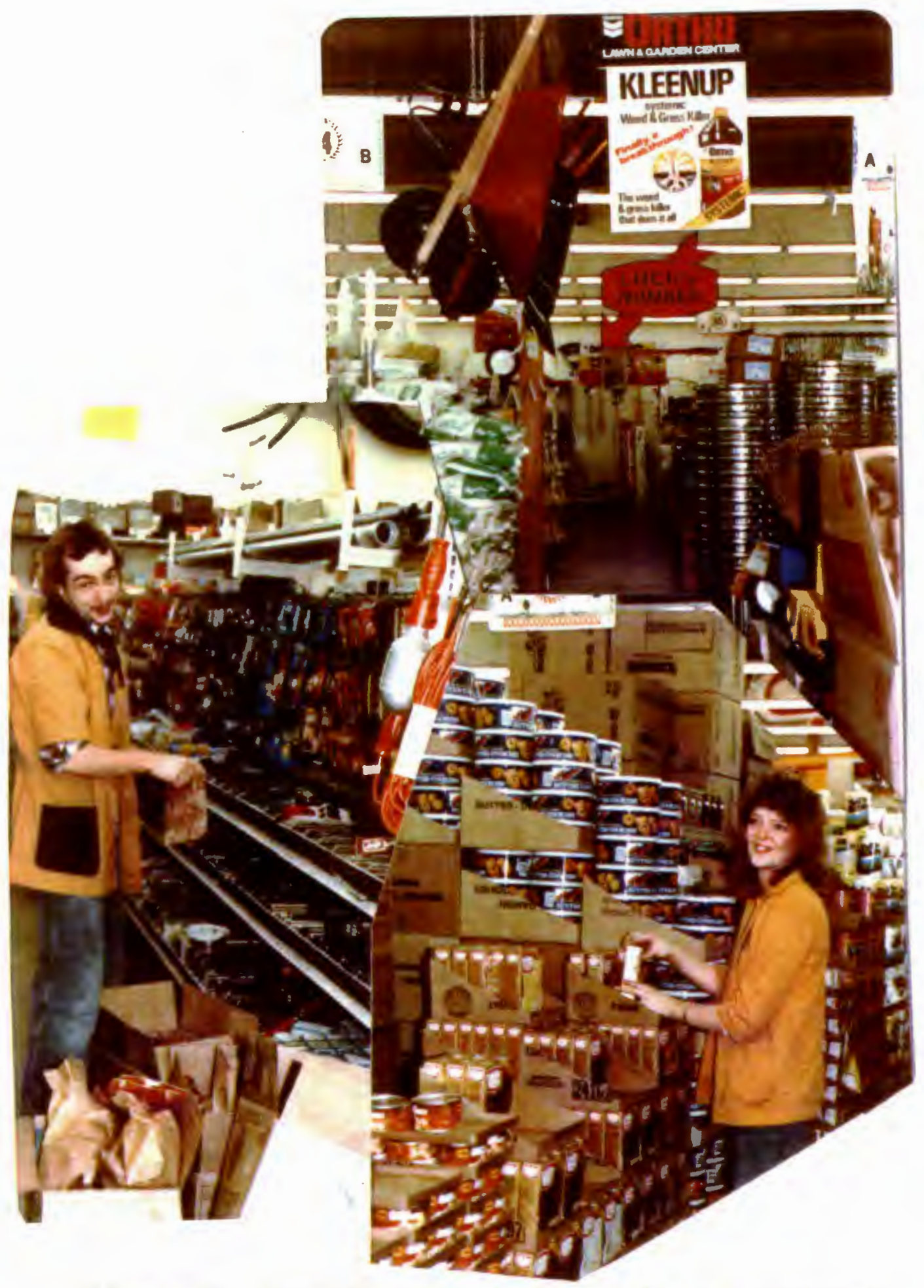

Eiqure 3. Into the departwents, clerks stocking shelves and arranging bulk stack 


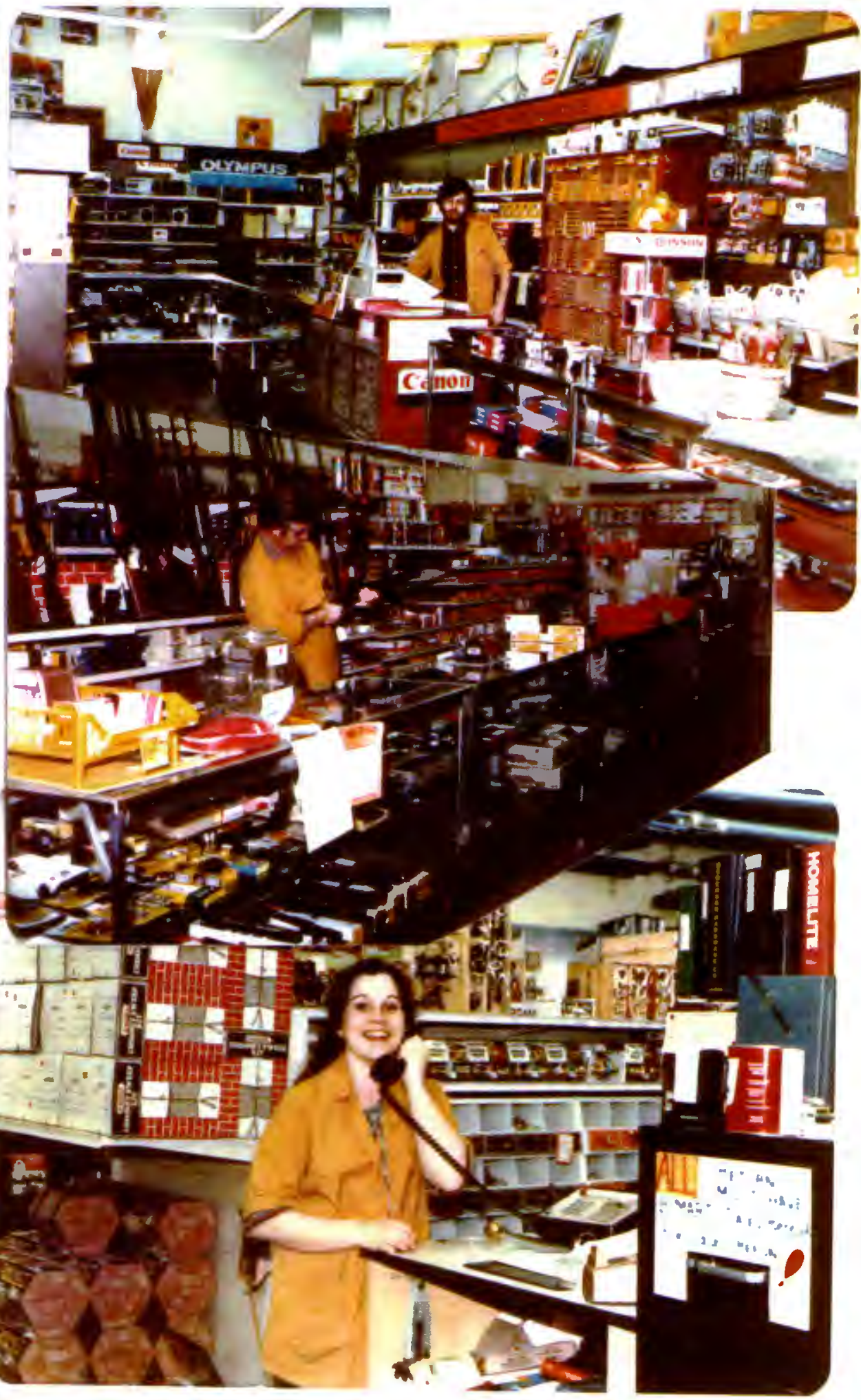

Eiqure 4. Department mangoors and clarks at their departant desk 


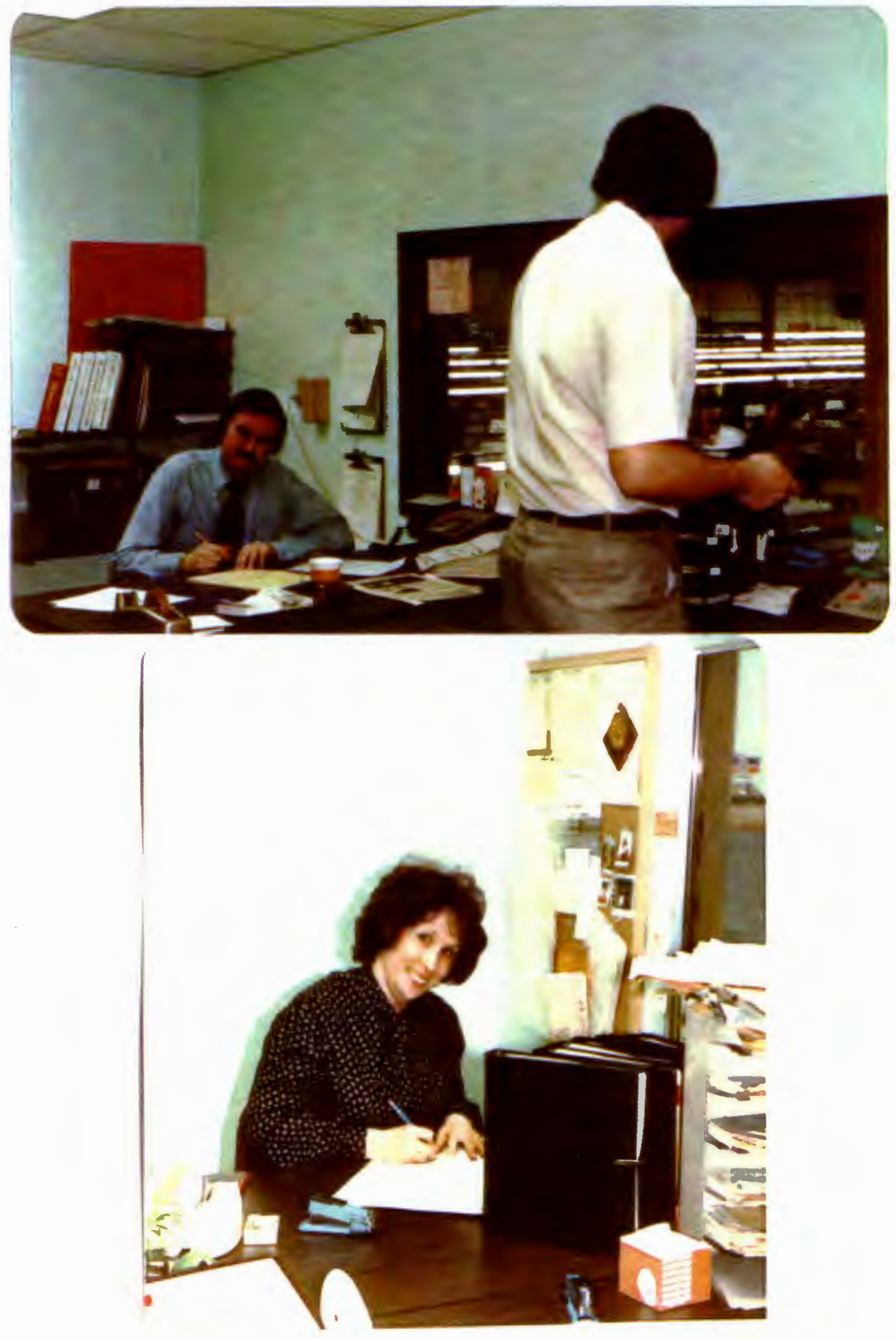

Figure 5, Into the office, the store manager, third-person, and "bookie" 


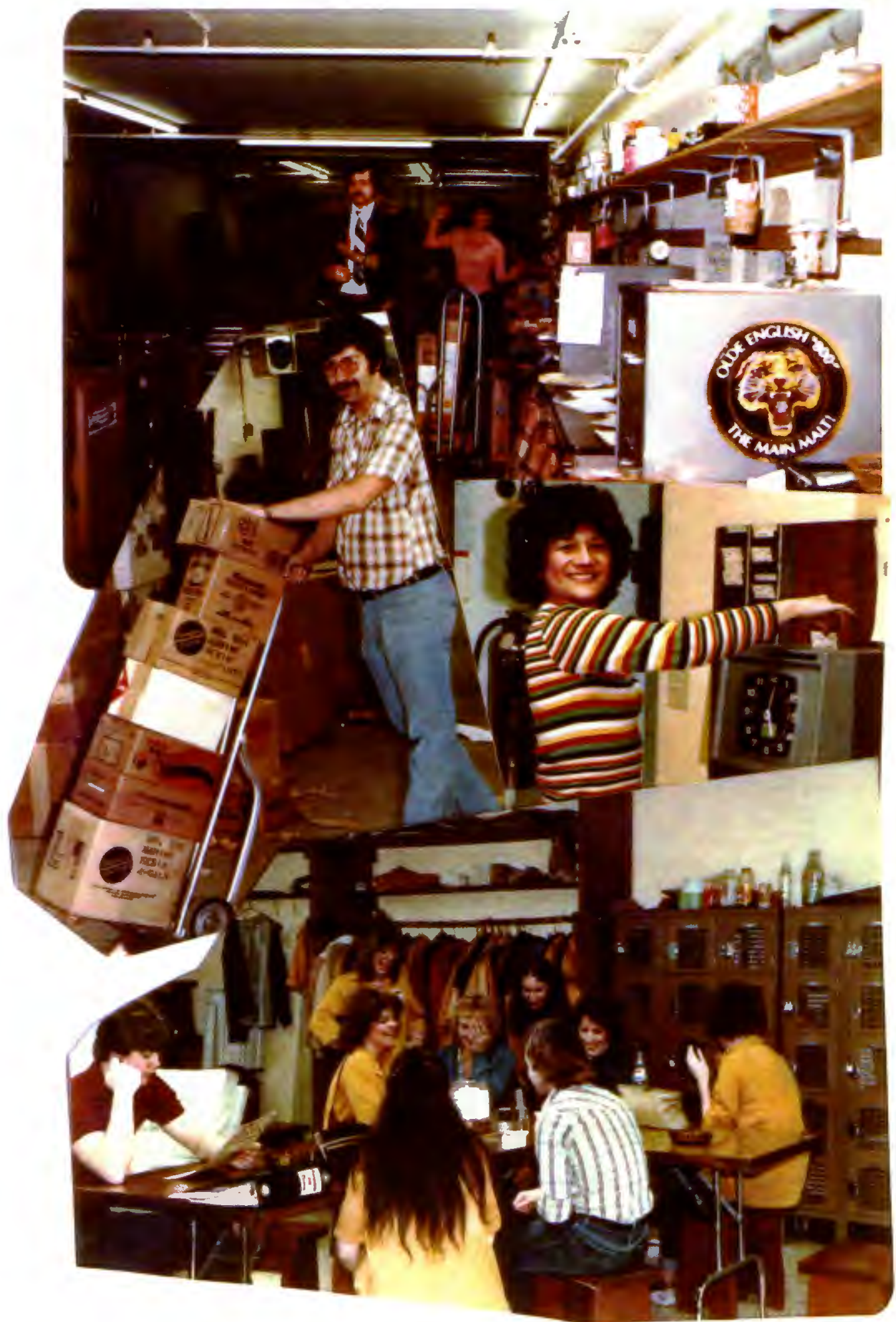

Fiqure 6. In back areass through the receiving department, a clerk "trucke freight", at the timeclock, in the "breakroom" 


\section{CHAPTER I I I}

\section{THE SCENE}

"INSIDE THE STORE"

Store space is allocated according to criteria which communicate cultural messages; these are mostly outside the awareness of participants, but these participants cannot escape even the hidden dimensions of their culture. Activities in a Bi Mart store occur within the context of building divisions UP/DOWN and FRONT/BACK as indicated in Table I.

TABLE I

STRUCTURAL REPRESENTATION OF STORE DIVISIONS

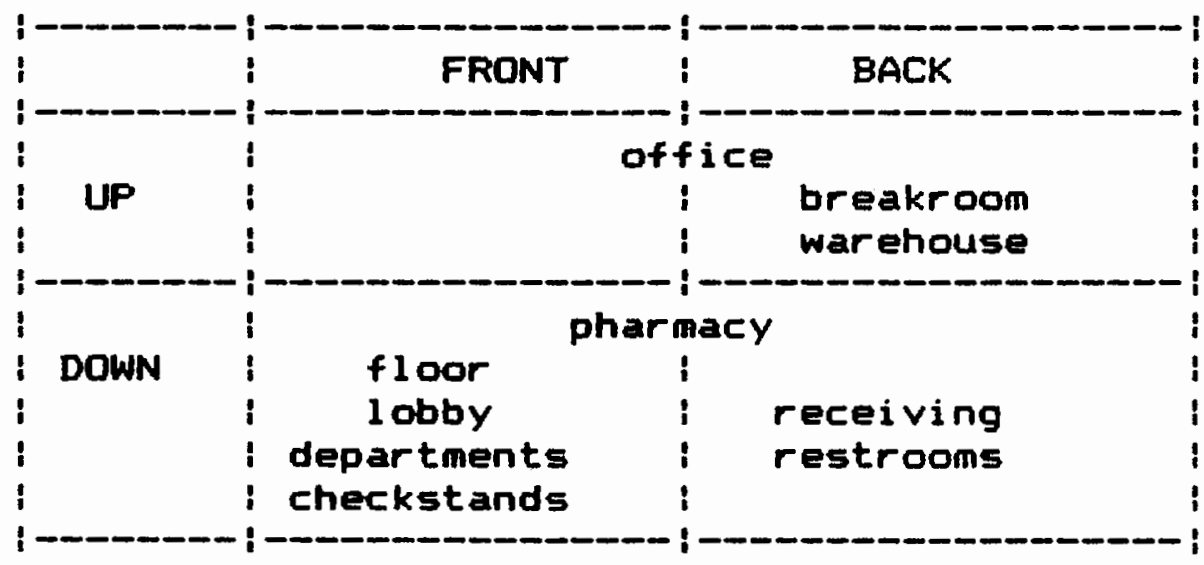




\section{UP/DOWN}

UP/DOWN serves as a representation of the store's social stratification. Store managers work upstairs in the office. Department managers, clerks, and cashiers work downstairs where they can be observed from the office above then through a large picture window. They may be directed from above via the telephone intercom system. As described by a store manager:

From the office on the second floor, we overlook the store. There are two telephones with intercoms in them. If I want to talk to Brian in the toys department I beep his desk; he may look up to acknowledge me. I can talk to him and nobody can hear us.

A complete taxonomy of store space, as shown in Table II, indicates that the upper level (which is small, 24 feet $\times 160$ feet, or approximately 4000 square feet) incl udes

A) the office, divided into the 1 arger "bosses" " office and the smaller "bookies" office, and the two are connected by a sliding glass window

B) the warehouse where back stock is stored in areas specified by department (see Appendix B, Figure 11), and

c) the "breakroom," a large room where employees come to "punch in" at the timeclock, to take breaks, and to "punch out." 
The lower level (which is large, 192 feet by 160 feet, or approximately 30,000 square feet) includes

A) the pharmacy, a cubicle partitioned off in the front corner of the store with windows opening inside and outside, where patrons come to pick up and pay for their prescriptions

B) the men's and women's restrooms

C) the "backroom," or receiving area, where merchandise arrives into the store and invoices are "logged" before items are unpacked and "checked in" .

D) the "floor," which includes

1) the "lobby," or front entrance, where membership cards are issued and checked as customers pass through to begin (hopefully) successful shopping sprees

2) the checkstands, where customers pay for their goods, and

3) the departments, including

a) housewares

b) photo-sound

c) toys

d) sporting goods

e) automotive

f) hardware

g) drugs

and h) beer/wine. 
Each department includes its own items, such as desk, telephone, calendar, "ad" book, inventory control book, "A - Z" book, "defectives" book, special catalogs, purchase order forms, and other color-coded slips of paper for special uses.

TABLE I I

TAXONOMY OF STORE SPACE

: OUTSIDE :

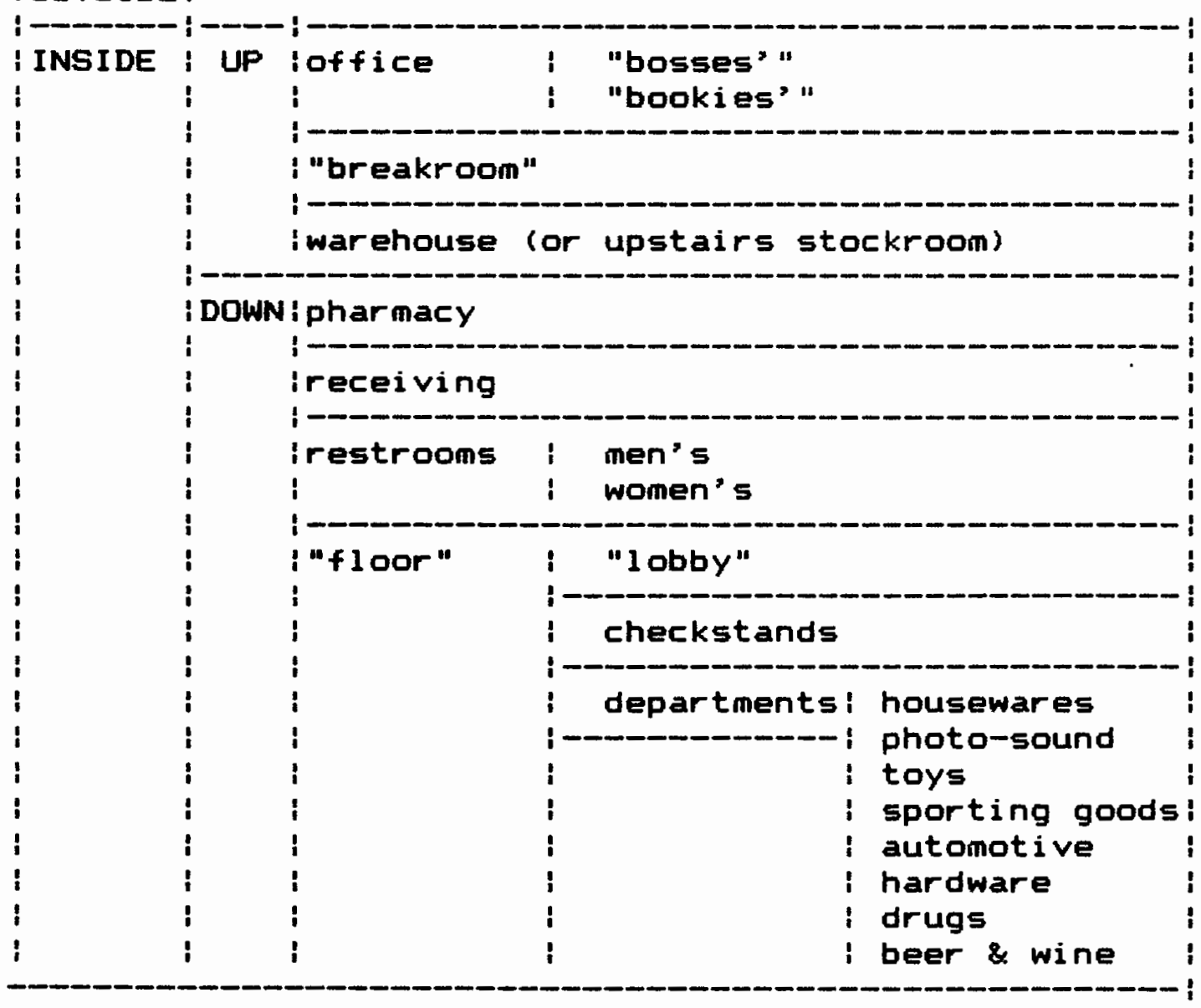




\section{FRONT / BACK}

FRONT/BACK areas may be defined and understood by application of the stage metaphor, i.e., all the store is a stage and we but poor players, etc. In front regions of the store, employees regularly perform particular routines and functions; dramaturgical success occurs when each performer knows the role to project from one moment to the next, properly maintaining front region control. In back regions, actions occur that are related to the performance but inconsistent with its appearance. Backstage, Bi Mart people can relax front regions postures; they may exhibit greater latitude in dress, language, gestures, and attitudes.

\section{The "Floor"}

At the front, the store entrance, or "lobby," is expressively bright. Here shoppers are greeted by an attractive, well-dressed receptionist who checks their memberships as they pass through a swinging gate into the departments. She thinks it is important to make a good impression, and says:

It makes people feel good when I say 'hello" and give them a smile. The whole point is to make them feel welcome. 
Front regions are public; patrons have access anywhere on the "floor." In the departments, each employee is expected to present a show of cheerfulness and helpfulness. And at the checkstands, considerate treatment of customers is said to be essential to their returning again and again. Bi Mart people pay attention to both customer compliments and complaints. Some compliments in the form of letters from satisfied customers are reported in a weekly Bi Mart newsletter, "What's Happening" (See Appendix B, Figure 16). Verbal feedback from both happy and unhappy patrons is usually passed on to any involved employee by the store managers.

Floor space is designed for maximum "traffic." As reported by a store manager:

It's like in the grocery business. The idea is to give" em the item; and if they need it, give "en the service; and supply' $\mathrm{en}$ with enough checkers at the front to get "em out of the store as smoothly as possible.

The number of employees on the floor is minimized; narrow aisles and the open floor plan allow one employee to take responsibility for a whole department if the volume of sales in that department does not require additional workers. 
The "Backroom"

The receiving department is a downstairs back region. It is cut off from the floor by two swinging saloon-style doors, and customers do not intrude. This area is drab and messy. Receiving clerks wear jeans and sweatshirts. As described by an employee:

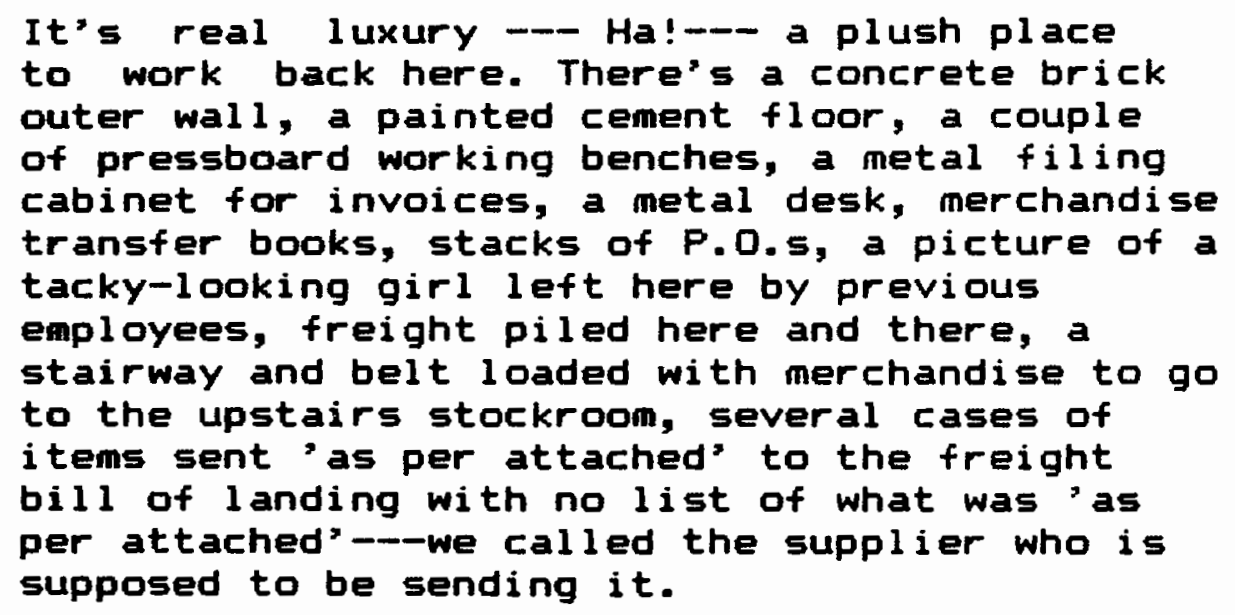

The building has two back doors. One is a garagetype vertically sliding metal door to which Bi Mart trucks back up and detach a trailer of merchandise from the D.C. warehouse. Receiving clerks move cartons off the trailer into the back room, unpack and price the items, and "truck" them into the departments. The empty trailer will be picked up at the time of arrival of the next D.C. semi truck loaded with another shipment. The other door is a heavy metal double door through which "studsy-looking" drivers deliver wholesale goods off the common carriers and beer trucks. Before the store opens 
at 11 A.M. employees arriving to work use this back entry---except for the three store managers who have their own keys to the front door. After 11 A.M., no employees are permitted to enter or leave the store by the back door.

The "Breakroom"

Back regions are private. Cashiers, clerks, and department managers seek refuge away from the floor by ascending the stairs to the "breakroom". Away from customers and out of sight of the office window, they have a place to relax. According to one employee:

So many miles everyday; it feels like a hundred miles from housewares to receiving and back again and again. That's why I like to come up here. It feels good to get off my feet and take a break.

Employees usually eat food in the breakroom, and often they share food, sometimes just for the sake of sharing cone may bring a freshly baked banana bread to set on a table in the morning, and another a bowl of plums, or box of cucumbers picked on a day off), and other times in ritual celebrations. An informant tells:

We're having a going away party for Susie who is transferring to another $\mathrm{Bi}$ Mart in another town. It's potluck. I brought ol ives; someone else brought potato salad. The bosses went together and bought the chicken. It's a way to say 'good luck'. 
Inside the four yellow walls of this roon workers find the timeclock, assigned lockers, rack for hanging smocks and coats, two bulletin boards (with work schedules, announcements, thank you notes, letters from previous employees who have moved away, cartoons, even a few official notices), excess shelving, and damaged merchandise for sale to employees at reduced prices lotherwise employees don't receive discounts for their own purchases). The room has a refrigerator, sink, coffee machine (the store provides the coffee), microwave oven (used to warm snacks and meals), and a telephone which can be used somewhat privately (it has four lines going outside the store and three "com" lines for inside store communications). People sit together at rectangular tables, which they arrange in Tshapes and U-shapes so persons are facing each other across and at corners.

Reciprocal first-naming is usual among all levels of employees, and anyone may initiate talk with anyone else. In the breakroom, discussions are generally available to all, but not necessarily joined by all. More than one conversation may be sustained by persons in clusters, possibly with some cross talk. Via shop talk, they may mull over past disruptions post mortem, and morale may be boosted. Sometimes they just talk 
about their talk. For instance, the following was overheard one day:

Some guy came back to hardware and asked, "you know this gum turpentine? Do they use it for medicinal purposes?" I said, "I don't know." Hell, he can rub it all over his body if he wants to but I'm sure not going to try it.

If workers are to succeed in maintaining the impressions of continual helpfulness on the floor they need a place to get away and "let it all hang out", smoke cigarettes, tell jokes, act silly, sing on or off key, quack like a duck, relax their speech, mumble, grumble, belch, loosen a belt, 1011 in an easy chair, or even lie down on an old sofa after a night of too much partying. There is some smart talk; for instance, when asked about the breakroom, one young man said, "The best thing I can say about it is that there are two good-looking girls sitting in here." These people enjoy open sexual remarks, even profanities, but decent appearances are usually maintained because interemployee and intersex impressions are important.

Peer pressure is a potent motivator at Bi Mart. Informal control through casual conversation in the forms of gossip, purposeful kidding, well-placed jokes, mimicry, veiled hints, and innuendos subtly aligns cohorts without challenging the definition of the 
situation. Many conflicts are thus quickly resolved. Troublesome co-workers are avoided physically, and excluded from joint decisions such as planning a party or sending flowers to an employee who is in the hospital), and joint ventures (such as going out to lunch, meeting at the tavern for a few beers after work, or short trips to visit friends at other Bi Marts). It is not uncommon for a group, or a clique, of employees to temporarily direct a negative focus toward a particular bothersome individual; it seems everyone (including myself) takes a turn as the victim. The group will persist until the individual atones for the error, or until the group switches its attention to another person.

According to a store manager, "a lot of important decisions are made in the breakroom," and he explained he did not mean at the store meetings which are formally called on occasion. Cultural fit is largely determined by interactions which occur backstage. Performers need an informal audience to try out vaunted selves and together enter into collusive intimacies. Breakroom activity functions to assure better onstage cooperation and performance. But it serves for more than show. Dealing effectively with each other depends upon accepting and sharing a set of rules, maps, and plans 
for organizing appropriate behavior for oneself and appropriate interpretations of the behavior of others. The breakroom provides a comfortable place for each of them to find out what it is "they are up to." In private, it is difficult to fool one's peers; employees either buy in or opt out.

store managers may use the breakroom (the third manager visits most often, the assistant manager drops in next most often, and the store manager rarely). They spend most of their time in the offices nevertheless when "customer service" is paged to the floor the third manager is usually first to leave the office and descend the stairs, and if he is away the assistant goes, and if the other two are not available the store manager must attend to the problem.

\section{The office}

The office is a mix of front and back activities. It is a front region where the "big man" status of a store manager is expressed by mere possession. In the office, a show of authority contingent with rank seems to be considered necessary in spoken performances with subordinates, salespersons, or customers; but with each other they are more relaxed. As described by the store manager: 
The office is functional. The floor is plain linoleum. The room is small, approximately fifteen by twenty feet. There is no space for people to congregate. There are two desks: one for myself, and one for the assistant and third person to share.

There are not strict rules of trespass to the office. According to Greg Jahnke:

It is "open-door policy'; people in this store have been told that the door is always open. Anybody that has a question is welcome to come to the office and ask. The door may be closed to talk privately to an employee to discuss any personal problem.

By sacrificing exclusiveness at the top, the morale of those at the bottom may be increased. Relaxation of distance and indulgent offerings of friendship generate feelings of involvement and common purpose, and expressions of favor elevate underlings to feel better able to accomplish goals.

The "bookies"" office is "teeny," approximately seven by ten feet. The two bookkeepers spend their days "pushing papers around," filing invoices for the departments in separate books, making sure bills are mailed to headquarters to be paid on time to receive cash discounts, and preparing daily bank deposits. Store managers depend on the bookkeepers to maintain records of store expenditures and sales. 
CHAPTER IV

THE PEOPLE

There are thirty-six fulltime people working in the South Salem Bi Mart store. More than half were previously employed in some other retail establishment; they came to Bi Mart because pay is better and working conditions are more comfortable. The remainder previously worked in higher paying jobs--the men in canneries or industrial plants or construction where they found the work both boring and dirty---and the women in restaurants or bars, where they felt unappreciated. When interviewed, all stated repeatedly that the intrinsic rewards of work are important. Thus job satisfaction to them involves the security of a steady income and health and welfare benefits and equally, enjoyable social interaction, interesting tasks, and a pride of accomplishment dualed with recognition for "doing a good job." Store hours (weekdays 11-8, Saturdays 9-6, Sundays 11:30-5:30) require only one shift of workers; this keeps 1 abor costs down and eliminates much need for parttime 
workers. Extra holiday help is hired, and many of these people request and take fulltime work when it becomes available. In contrast to other stores with turnovers of pergonnel up to 4-5\%, last year turnover of employees at Bi Mart was 1.88\%. This low turnover permits development of inside talent.

For each Bi Mart employee, there are two forms of social bonding and identification:

1) to the collectivity through employment. This comes from the role a person plays as an employee within a formal division of labor. Categories of employees are differentiated by title and ranked by position and pay, and statuses of individuals change as they build up experience with the company.

2) to other individuals through social relationships defined via informal social interaction. New employees aren't told about this special network of insiders which overarches work roles; but formal stereotypes dissolve as individuals become known by their personal behavioral attributes---eg. "peacemaker," "goodtimer," "sexy," "gay," "silly," "sweetie," "bitch," "hot dog," etc. It is impossible to remain detached from this Bi Mart so-called "family"; individuals who don't fit don't stay very long. 
THE INFORMAL NETWORK: THE BI MART FAMILY

\section{Insiders/Outsiders}

Any person entering the Bi Mart store is first recognized as an insider or an outsider. Of course, by entrance alone any person is an insider because Bi Mart membership is required to enter, but this rule is not always strictly enforced. But the true definition of insider, as understood by informants, depends on cultural fit. 'Insider/outsider statuses are sorted in Table III. Generally, insiders are Bi Mart employees, but exceptions are made for some spouses, girlfriends, boyfriends, and a few regular salespeople.

TABLE II I

\section{INS IDERS/OUTSIDERS}

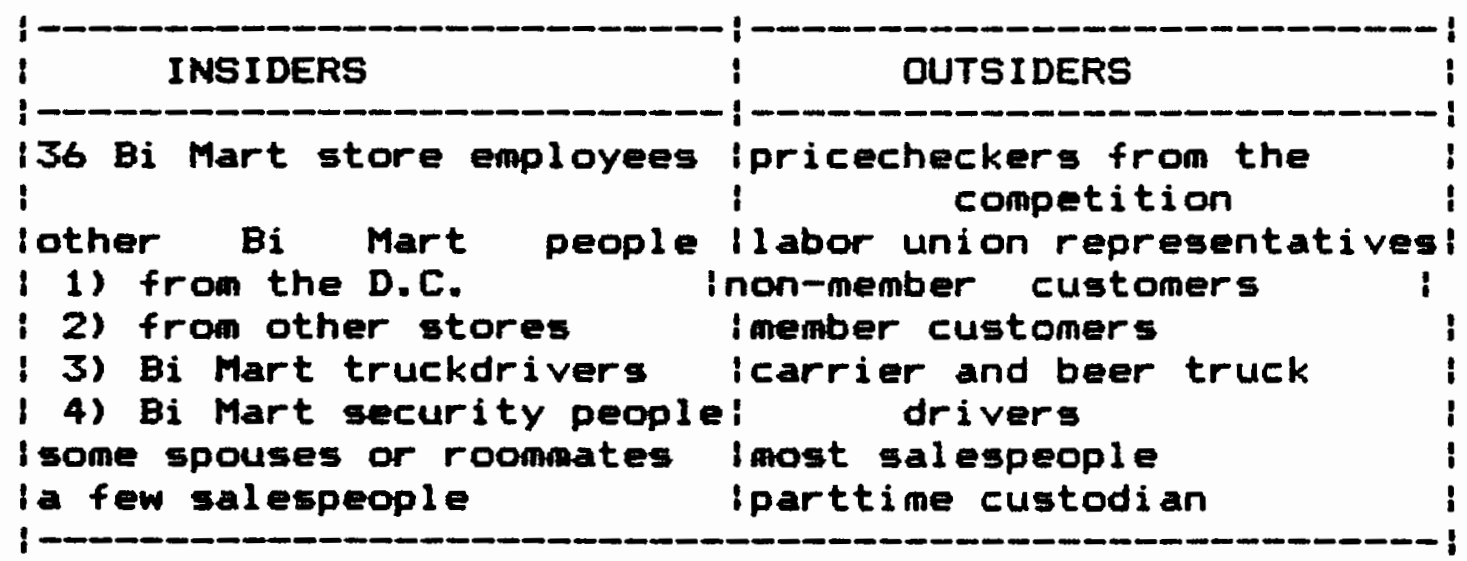


For most insiders, the store is their life center. They anchor themselves, psychologicallyspeaking, to the Bi Mart company as home-base and, socially-speaking, to the particular Bi Mart store as home-away-from-home. These people rarely participate in broader community lifes instead they participate in the store community.

\section{Affect and Sentiment}

Many people yearn for the good, old peasant community in its simplicity. In a highly anonymous pluralistic society, these people are hungry for some palpable signs of their collective transcendence and for some kind of security against the anxiety of not being able to comprehend their complex universe. Bi Mart society functions to shield. its members from an impersonal surrounding world; inside the store, people know who they are and they know somebody likes them. Meaningful direct attachments among individuals are possible because the group is small and social interaction is frequent. Because of repeated relocation from town to town and work schedules of evening and weekend shifts, Bi Mart people have few opportunities to establish long-lasting personal relationships off the 
job; so they meet people like themselves with whom to socialize on the job.

Bi Mart employees become good friends who give each other rides to work, spend lunch hours together, and after work meet at the tavern across the street. They are open with each other, and they enjoy direct eye contact. There seems to be a general sense of benevolence among then. In conversations with me, they appeared eager to divulge information about themselves and willingly discussed the subjects I pursued in the interviews. Not a single individual objected to my use of the tape recorder.

Off the job, they profess social egalitarianism. The group is not centered about a few particular individuals, though some persons choose to initiate more activities than others. Strong affective bonds are to each other, not to the store manager or their particular bosses. Store employees join BMEA (Bi Mart Employees Association, a chainwide, non-profit organization) and share in the organization of store functions and celebrations; they pay dues, sell baked foods or hot dogs, and hold contests to earn money to sponsor BMEA activities. They also give parties in their own homes; the host or hostess tacks an invitation to the bulletin 
board above the timeclock for all to see, with the date, time, type of function, and a map to her or his residence. Invariably there is something happening, and most insiders look forward to attending the parties. Regular attendance, which is not required as part of their jobs, indicates their strong desire to be included in these social activities. Their talk reflects the importance of these get-togethers and good times to them.

On the job, store workers adjust to one another and cooperate well in performance of complex, routine tasks. For instance, "ad-breaking" involves contributions from employees at every level in the store. A few weeks early, department managers receive "ad-notices" from their department buyer, and department clerks inventory ad items, suggest an order to the D.C., and write up a P.O. During the next few days, this order is shipped to the store. Receiving clerks unpack the items, code and price sticker, pintag or stringtag them according to P.D. specifications, and "truck" them into the departments. They also log the invoices, and take a copy to a bookkeeper. Department employees shelve and display the items, and hang "ad signs" which are sent from the D.C. "Ad sheets", or lists of ad items and prices, are sent to department employees and cashiers. 
Meanwhile, the store managers receive the "blue line", or blueprint of the ad, from the local newspaper. The department managers "proof" their parts of the ad; then the store managers, from both stores affected by the ad, concur that all is correct. On the morning when the ad "breaks," or comes out in the local newspaper, the receptionist displays "tear sheets," or ad copies torn from newspapers, in ad display cases in the lobby and at the checkstands. While the ad is "on," or in effect, clerks and cashiers 1ssue "sorry slips" for ad items sold out, and department managers record their number for future reference. This process is in continual flux within the store because as soon as one sale is over another begins. Day in and day out, it is important that every person do their part toward completion of the wholes interdependence of this sort reinforces community sol idarity.

\section{Eictive Kinghip}

Human beings are banding animals; they learned to live in families and are not likely to learn to live without them (Bohannon 1980). Bi Mart employees find it difficult to maintain kindred relationships when promotions require moves away from hometowns and restrictive work schedules limit travel time--- 
especially during the holidays. To meet the needs and serve the functions of families they may not otherwise enjoy, Bi Mart employees create an artificial bond of kinship with each other: they carry the ideas, sentiments, and loyalties associated with kin beyond the sphere of actual ties. They show pride in membership and collectively refer to themselves as "the Bi Mart family." One informant describes:

Every store has a feeling, a family feeling. When I worked in the Albany store it had that. feeling; and the Bend store toos in this store, too, employees are particularly close.

This is a chainwide phenomenon which transcends locality and functions to maintain the historically-derived traditions through the grapevine and via the weekly newsletter circulated to all the storas.

Story has it that a few men, as founders, started Bi Mart as a cooperative in someone's garage. Membership allowed them to sell name-brand products below fair trade prices. Their idea worked, and they built their first store in 1955. One store led to another. Some of the Bi Mart people stayed in the first store, and some moved to the second store. Those persons, who were familiar with the method of their successful first operation, vigorously adhered to those definitions which had been most expedient for them, and 
taught them to the new recruits. What paid off in the first store in the first town also paid off in the second store in the second town, and then in a third store in a third town, and so the story goes.

Frequent splitting off of workers to different stores in different locations was effective for recruitment of experienced people into new stores, and also permitted people in different stores to maintain in-tact relationships to each other via a large body of common knowledge which sprang from their past, and some of which could be traced back to the original founders.

At the store level, members are firmly enculturated into the "family" customs. In the small group, work is personal and intensive, so that it is easy for people to discover the connections between their actions and the consequences of them. And though persons move among stores, they allocate loyalty to, and adopt identity with, the store in which they work for that time. In particular, individuals incorporate new friends and alliances, and they compete with new persons for promotion and favor. In general, they adapt themselves to "the personality" of the store; according to an informant, "each store has its own personality" which depends, I am told, on the distinctive 
personalities and policies of the store managers. Finally, in stores as local units, they enter into a spirit of competition with each other, and also they align with each other to compete against payless, G.I.Joe's, Fred Meyer, K Mart, and other discount retail companies.

Thus Bi Mart came into being, not by design, but in a series of reactions to the needs of present moments. Via this pragmatic approach, the company developed a framework of social and political structure, as a "family," which is economical and eliminates a need to recruit outsiders, except at the botton levels. This reinforces insider solidarity. Furthermore, it functions to reduce internal conflict. Employee transfers occur as reciprocal arrangements between stores because a sense of equality exists among workers of the same status in different stores.

Freud believed that the mediation of cultural contradictions occurred within the family in interactions more or less universally repeated in the common experiences of family life. This seems to be true for "the Bi Mart family"; the hard edges of economic relationships (employer/employee) are softened. Obligations due center around support; superiors support inferiors in their endeavors, and vice versa. And 
friends "are right in there trying to help" when someone accidentally runs into trouble. The "fanily" requires close cooperation among members in the groups and at the same time tries to accomnodate their divergent and competing individual interests.

Except for child-rearing, it would seem every function that families perform can be done just as effectively by the store "family." Interestingly, almost three-fourths of store employees are singles (including divorcees) and couples without children. There are five couples between the two Salem stores (four heterosexual, one homosexuals. Employment for married couples is maintained by the company, but in separate Bi Mart stores. Marriages between employees allow couples to coordinate their work and play schedules. And they can pool their salaries to acquire the material well-being of a higher middle class lifestyle which they otherwise could not afford while working at Bi Mart. However, marriages may hinder promotion because couples don't like to take a chance on losing one income; promotion may be delayed when, with each long-distance transfer, a second job in a nearby Bi Mart is requested for the spouse. 


\section{Male and Female}

In every culture, a set of cultural definitions is imposed upon the biological differences between male and female. Male/female interactions are an important feature of the Bi Mart cultural scene; both male and female informants report they prefer the mixed-sex to all-male or all-female work environments. Similarly, their play environments are mixed-sex. The same men and women who work together play together; they meet in pizza parlors and taverns and each others" homes to relax, eat, drink, and listen to country or rock music. Many of them love to dance. They joke, laugh and get rowdy to have a good time together. They swap gossip, exchange funny stories, toss out clever witticisms and verbal quips in fact, the men and women best at communicating and interacting in this extroverted style often win support for promotion to better jobs. Some informants say it is "kiss ass," but one told me, "drinking with boss isn't a requirement for promotion, but I enjoy it."

In social contexts, feminine behavior is usually the antithesis of masculine behavior at Bi Mart. Persons of the opposite sexes style themselves in ways which attract. They are good-looking people, who are, in 
general, concerned with appearances, and, in particular, they choose friends and partners who are also good-looking, dress in style, and drive nice cars. Joking relationships occur between people who are possible mates (Spradley and McCurdy 1975). The men and women at Bi Mart banter, tease, and impress each other. In jest, they like to "give each other shit" and exchange insults, and instead of taking offense toss back more cutting remarks to "put down" a supposed adversary. In the group, they tell each other stories which would normally be taboo for conversations between men and women. This kind of patterned flirtation and verbal license serves as an emotional safety device and gives overt expression to sanctioned intimacies. Individually, they buy each other drinks, make dates, and orive each other home.

Premarital affairs, including cohabitations, are socially acceptable within the Bi Mart community, and, in fact, advocated by some members. Extramarital relations occur, and usually a feigned and futile attempt is made at secrecy. Though it is not considered in good taste to act as an informer against these persons, such affairs are not really considered scandalous. Insiders are free to choose their own styles of intimacy and are not ostracized for their 
preferences. In this vein, the attitude of the group toward homosexuality is a tolerant one. However, amidst this atmosphere of sexual leniency, liaisons between managers and their subordinates are generally frowned upon because such affairs are usually distracting and deleterious to the normal functioning of the system. And consequent to either resultant marriages or resultant divorces, the company becomes besieged with transfer requests. Employee transfers are often made for purposes of dissociation.

In work contexts, male and female are not supposed to be two different forms of organization at Bi Mart. Informants say that men and women ought to follow the same rules and have equal access to success; good managers are not determined by sex but by individual motivation and development of talents. But men have been more successful. Division of labor by sex is charted in TABLE IV. M/F ratio i\$13/23 overall, and for managerial positions $M / F$ is $7 / 4$. As indicated, women are managers only at the department level; and each of these four women report they worked harder and waited longer to get to their positions. 
TABLE IV

DIVISION OF LABOR BY SEX

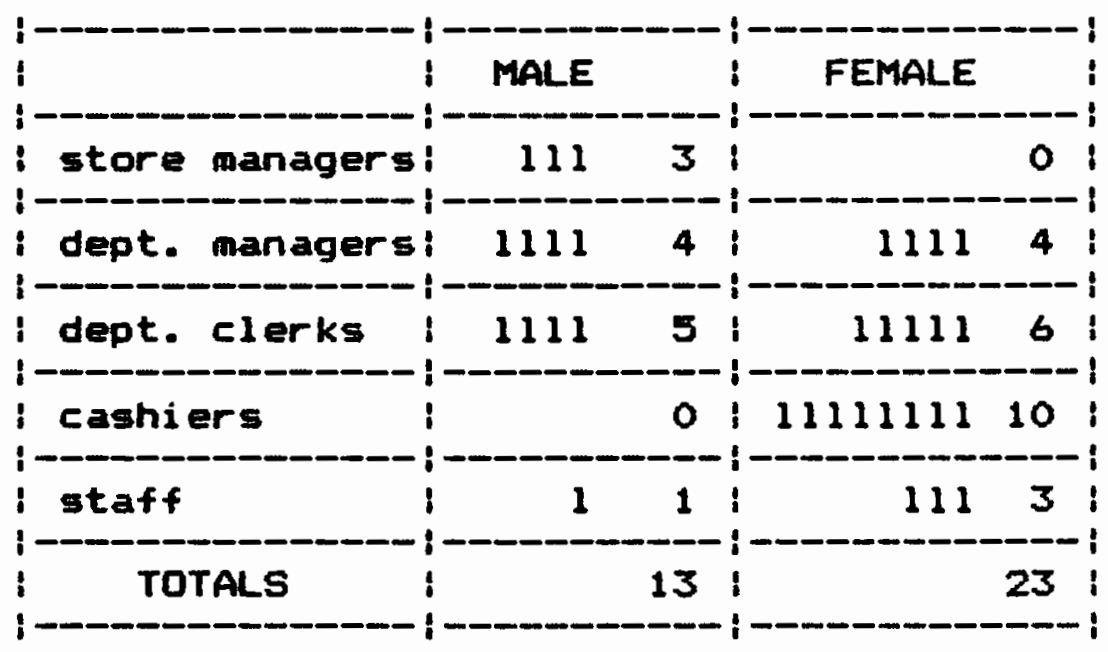

Pay is by position, and is the same for men and women of equal title. Informants conclude that starting wages for women at Bi Mart are high relative to what they could earn elsewhere; in general, this is not true for the men, though pay is higher for them in retail work at Bi Mart than in other stores. This could result in more intense competition among the many women, and less intense among the men.

However, not all the women who work in the store are motivated to become managers. Those in their early twenties are more interested in getting a husband than in getting a promotion, and with or without a husband, in having a baby. But after one or both of these aims 
are achieved, they come back to work to meat expenses. Some women are unwilling to relocate; they are tied to husbands with incomes from jobs in town and think of their own salaries as second incomes. These females see themselves peripheral to males and accept passive roles as order-takers; they refer to themselves as "girls," as most of the men refer to them.

other women are motivated to become managers. They are willing to relocate to attain positions as order-givers. Like the men, they learn to come right out and ask for what they want. But these women have to be more patient than the men to get a desired promotion. Interestingly, a woman in the South Salem store has been chosen as the store's candidate for MRP (Management Review Program), while she waits for a promotion to third manager, men from other stores with less company experience pass ahead of her and ironically, the men in the south salem store complain they therefore have to wait longer to take her place in line.

\section{THE FORMAL HIERARCHY}

A store, as a workplace, is not industrial in the strict sense of factories and assembly lines, but its formal organization is characteristic of industrial 
society. Participants at Bi Mart are laborers in a wage economys participation is by a kind of specialization within an hierarchical division of labory and the individual" s search for higher status in the store takes place in an hierarchical world at large.

Work at Bi Mart is divided up among four categories of employees: 1) store managers

2) department managers

3) clerks

and 4) castiers.

These divisions are not casual. Employees use these categories to identify persons, anticipate behaviors, and plan for performing roles. And a sense of security cones from knowing one"s place in the pecking order. The organization chart in Figure 7 identifies persons by position and title, and designates the vertical relations of power and authority. As indicated, the store operates under a "three manager system," with a top management team composed of the store manager, the assistant manager, and the "third-person," or third manager. There are eight middle managers. Each is charge of one department in the store: housewares, photo-sound, toys, sporting goods, automotive, hardware, drugs, and receiving. There is a number of clerks assigned to each department depending on the required 


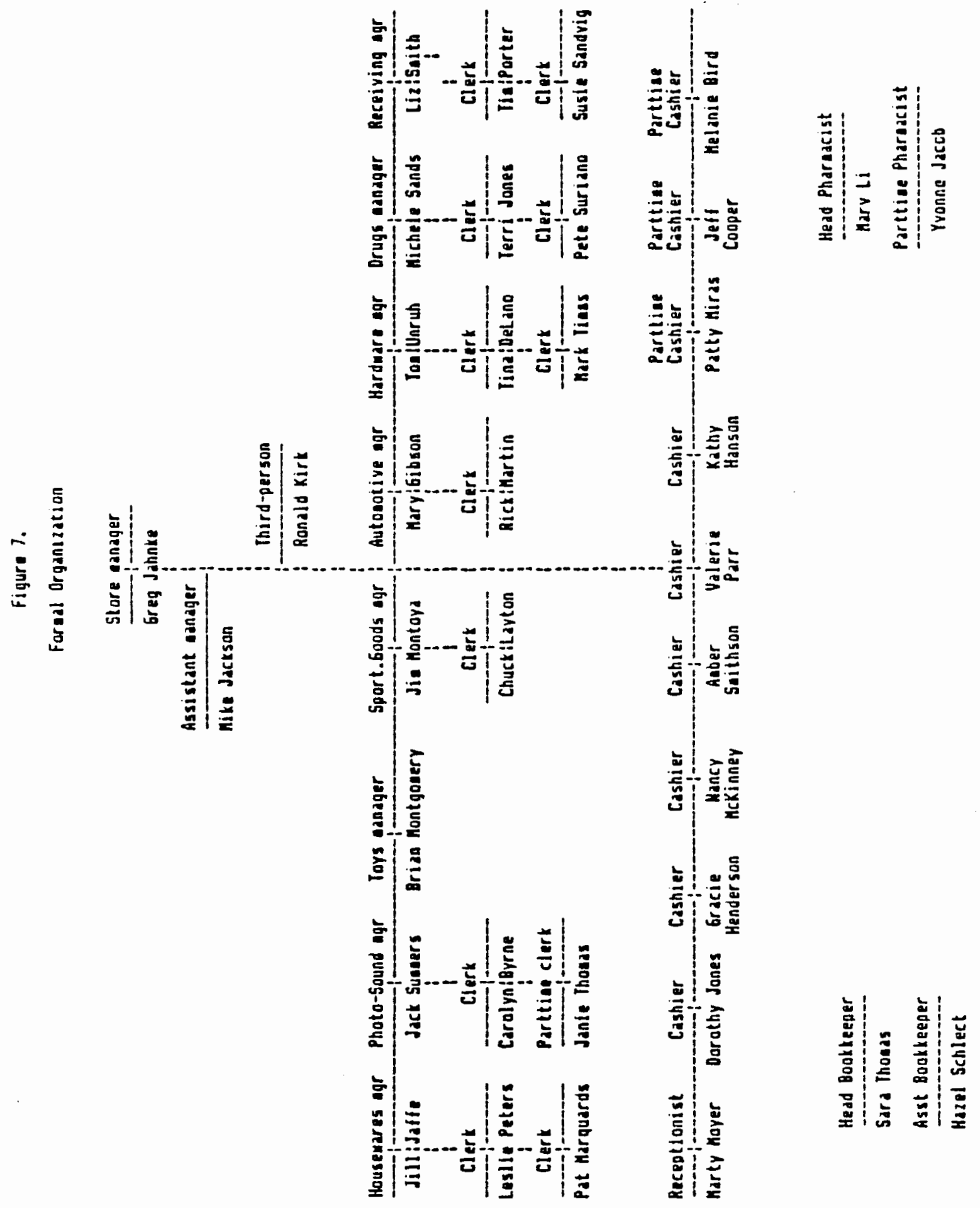


amount of customer service and the volume of sales in that department. There are six fulltime cashiers and three parttime cashiers. There 13 one receptionist. Staff employees, who are not in 1 ine for promotion along the lines of the chart, include a head pharmacist, a parttime pharmacist, a head bookkeeper, and an assistant bookkeeper.

Subordination is imposed by this framework. Nevertheless, potential rifts within the vertical structure due to conflicting interests (management/labor) are partially mitigated 1) by reaction of strong affective bonds, which diagonally cross categorical boundaries and allow for a kind of formal/informal compromise and 2) by an esprit de corp, a personal identity with a company in which employees feel they have a stake. Furthermore an undercurrent of interpersonal conflict due to horizontal competition for opportunities and rewards is mediated 3) by aspirations of advancement which depend, not only on the good will and support of superiors in particular, but also on getting along with others in general, an ability highly valued in this subculture. Also 4) sharp distinctions are blurred by the idea that relations are temporary. A person in a subservient position this year may be in a position of some authority next year or in three years. 
Smal 1 disruptions are usually resolved through informal social control in miniature versions of the judicial process ritually repeated and enacted. At Bi Mart, the best defense is a timely joke; learning to interact in an appropriate joking manner is an intrinsic part of belonging. Sometimes an interactional offense must be vindicated by a penance of some kind, preferably on the spot, to allow acceptance back into the good graces of associates. When an infraction is small--such as a show of temper, or not "pulling your load" for the day---it is easily assumable and the penalty is also small---such as offering an apology, pleading an excuse, "passing the buck," or granting some request as compensation. Hithin the formal structure, an informal atmosphere of easy interaction and sociability makes such accommodations possible.

Additionally, the status hierarchy is played down because employees style themselves as a team. Teammates are sometines required to subordinate individual objectives in unswerving loyalty to the teams their ability to do this in the long run helps them achieve their individual goals. They recognize the importance of the store manager who coaches and calls the signals for the good of the whole tean. Together they celebrate 
the wins. This gamelike conception of Bi Mart work softens the maneuverings for the unequal pay. offs. But the perception of the game depends on the relative positions of team members.

Individual participation is limited by the status of the individual within the formal hierarchy. Role assignments are outlined. Employees interpret situations, actions, and events depending on their knowledge of the cultural elements built up during their experiences with the particular roles. Accordingly, they view their Bi Mart experiences differently at different stages of their careers. Cultural perspectives from the top, from the middle, and from the bottom levels were revealed in conversations and interviews, and are reported in the next three sections of this chapter. Their views aren"t always formulated with precision, but repetitive bits and pieces form recognizable patterns. Thus, valid inferences can be made about each perspective which give it overall meaning within the larger context of the cultural scene as a whole.

VIEH FROM THE TOP

Three store managers present a united front. They don't claim unfettered individual freedon, but 
stress instead mutual interdependence. They "try to combine their best features and compensate for each other"s shortcoaings." Together they work to show a profit in their store; this is the index of their achievement. They are always talking about "making payrolls" and "meeting projections." And they are compensated with regular salaries and quarterly bonuses proportionate to their own store profits. A store manager receives $3 \%$, assistant $1 \%$, and third-person 1/27. In this calculation, all losses during the year are cumulative, i.e., winter quarter (Jan Feb Mar) losses are subtracted froa spring quarter (Apr May Jun) profits, or added to spring quarter losses and subtracted from sumaer (Jul Aug Sep) profits, and losses from winter, spring and summer are subtracted from fall quarter (Det Nov Dec) profits which are usually biggest due to Christmas.

Store managers motivate their employees to produce for then by lesson and by example. They enjay superior status because they say they have earned it; they have "come up through the ranks" to their positions at the top where they give orders and expect then to be carried out. They have autonony to go about their work as they see fit. A store manager told me there is a 
thick company rule book; he said he was asked to sit down and read it once when he became third-person, but he doesn't always "go by the book." Instead of focusing on restrictive negatives, Bi Mart managers are encouraged to reinforce the positives. They downplay discipline; nevertheless transgressive actions which threaten their legitimacy are sometimes put down with a show of power. However, "big stick" managers are not tolerated by the company; everybody knows that store managers may be put on probation and fired by their district manager. Good store managers remember their own struggles as underlings, and they are quick to remind subordinates they are familiar with their problems. Store managers try to offer succor and support. They worry about stagnation and look for ways to give any needed push to increase productivity, and thus increase store profits.

\section{Greq Jahnke ane 45}

A divorce forced Greg to sell his own business and seek work with Bi Mart. He was hired as a clerk, and in three months, "before I had time to think about alternatives," was promoted to sporting goods manager. He says: 
I busted my butt, and did a good job for 'em--stocking as much dog food and stacking as much oil as anybody in the store. I did what was expected of me.

He worked well with the assistant manager, and within eleven months Greg became third-person, or as he describes, "the person between the store managers and the floor." He found working at Bi Mart "fit my type of 1 i festyle."

Greg says he earned a reputation as "peacemaker"; he was called to Ashl and because the company needed such a person there. Greg tried to refuse the transfer because he didn't want to move his hundred-year-old "pa"; however, he "was told the "facts of life"---the company wanted me to move to Ashland." Things continued to go well for Greg, but not so well for the other two store managers who were fired. Greg "was given the store." His goal had been to become a store manager in five years, and he just missed it by a few months.

Greg was asked to move again to Salem, and has found operating a brand new store a new kind of experience. He describes:

You have younger people eager to get ahead. Some of them don't care who they might step on to benefit themselves; a few wanted to get ahead by running other people down instead of producing. I made damn sure they got out of this store. 
Mike Jackson, age 27

Mike is bright, handsome, and "a real hardworker"; he is ambitious and says he "likes meeting a challenge on the job." And he is very popular with employees who respect him for his sincerity and forthrightness. Mike came west from Kansas when he was twenty. He was hoping to "take opportunity by storm," but he was disappointed. After he was hired as a drug clerk in a Bi Mart store, he said, his "potential" was recognized. He "set a goal of five years to upper management," and told himself, "if in that time I didn't make it with Bi Mart, I would leave the company."

He transferred to the orug buying office at company headquarters as a secretary, to "get more knowledge about chain operation." He learned buying procedures, but found no opportunity to get ahead. So Mike asked to go back into a store. Within two weeks, he was given the position of drug department manager in a high volume store, and "thrown back into the middle of the action." Mike became close with his store manager and, upon being asked, offered some ideas about i aproving the housewares department. He says, "the next thing I knew I was housewares manager," and he found out "managing is technique." 
"With a push from his friend, the store manager," Mike moved to another town to become third-person and meet his goal "to move upstairs." Next he moved to Salem to take a promotion to assistant manager. Mike says:

I had made up my mind that to get anywhere in a reasonable time I was going to have to be willing to roll with the punches.

\section{Ronald Kirk, aas 30}

Ronald is analytic; he is not aggressive, but he is enthusiastic. He ran the most successful United Way campaign within the chain this year for which the store received a special letter of thanks from the company president.

Ten years ago Ronald returned from a cross country summer trip knowing he didn't want to go back to school or return to selling shoes. What he really wanted to do was buy a camera store but he says, "I needed money. And I needed more knowledge. Both entailed getting a job in a camera store somewhere."

He found employment as a photo clerk in a Bi Mart store. "Moving was really no problem---just put everything in my pickup and go. I didn't have any roots." After three months, Ronald moved to another Bi Mart store in another town to take a promotion to 
photo manager. But, during his third year, Bi Mart bought out his department, which had been a lease department. Many of his responsibilities were taken away from him. He "saw this as a step down, and had a hard time adjusting," so Ronald took a leave of absence. When he returned to work in another Bi Mart store he soon became a drug department manager. He married a "gal" who worked in the store. When Ronald accepted a promotion to third-person at South Salem "it was "a neat opportunity" because his wife could transfer as a clerk to North Salem.

Ronald values his ten years experience with Bi Mart and is still interested in learning on the job. He describes:

It's not text-book learning; it is getting into situations. There is no answer in a book to do this in this situation, do that in that situation.

As a store manager he has learned the following:

a solution is compromise. A first person wants this; a second person wants that. I try to work out a "third alternative' that makes them both happy.

\section{VIEW FROM THE MIDDLE}

Middle managers respect the position and authority of the store managers above them, though they say they would do some things differently themselves. 
As department managers they pay special attention to the instructions and requests of store managers because it is important to gain their personal support for admittance to MRP and an eventual move up to thirdperson. Competition is stiffest among department managers. At present, 224 department managers compete for 28 third-person positions. Yet there is a cooperative spirit among them because they share common interests and problems. They spend most of their time making order for merchandise to fill the shelves of their departments. They teach departmental procedures to their clerks, and, with their subordinates, take turns answering cashier inquiries about locations and prices of the products in their department. And they help customers who need special information about these products.

\section{Liz Smith, age 34}

Liz is attractive in a careful way and articulate in a casual way. She has a great sense of humor. She wants to get into top management and figures if she "waits around long enough they will have to move me upstairs eventually." She doesn"t want to leave the Willamette Valley, but she does want a promotion and "will move anywhere to get it." 
Ten years ago, Liz was trying "to work two terms to go to college one." She became a guinea pig for a friend studying psychology, and found out her I.Q. is between 120 and 130. She says, "that made me feel pretty good, and gave me the gumption to set out on a new, more direct course." She was hired as a cashier for a Bi Mart store and soon became back-up receptionist. She transferred to another town to become a drug clerk, and reports:

thereafter I found it difficult to get a promotion, being female. I found myself training a fell ow to be my boss who knew so much less than I did that I started making a little squeaking here and there.

Eventually she was promoted to drug manager in another town. A year later, her store manager made her housewares manager. But she found herself "in the middle between two bul1s," because the store manager was an ex-housewares buyer. So she lateralled to Salem. After a short while Greg transferred her from housewares to receiving so she would "broaden her experience," and he sponsored her for MRP. Liz explains:

With expansion, Bi Mart is looking for qualified managers; they feel stuck with some they promoted in the past. So guidelines have been set for qualities like leadership, stress tolerance, comanication skills...

Last month three company observers came to the store to watch Liz at work. Also, with other the MRP 
candidates from other stores, she attempted a 90 minute basket routine, or handling of a situation described on papers in her basket. Liz didn't complete her basket, but she"was headed in the right direction." And she participated in role-playing exercises and leaderless discussions. She reports, "The quiet ones got "NO". I made myself a "QUESTIONABLE", but I got a "YES'." SO Liz met the test but is still waiting for the promotion.

\section{Jim Montoya age 50}

Six years ago Jin left Nabisco Company to cone to work at Bi Mart as a drug clerk. Soon after, he was promoted to drug manager in a new store that opened in another town. However, he was unhappy in the second store because his store manager wouldn't support his decisions; so Jin took a leave of absence. Six months later he went to work in a different Bi Mart store as a hardware clerk, and in that store he lateralled to automotive clerk. He agreed to make another lateral move to North Salem when his wife was hired as cashier for the South Salem opening. A year later Greg offered Jim a promotion to sporting goods manager/ so Jim and his wife switched stores. Now Jim hopes Greg will recommend him for MRP because he wants "to go as far as I can as fast as I can." However, because he is older, 
Jim fears the company may not want to invest in his future.

Mary Gibson, age 29

Mary got tired of cocktail waitressing so she took a job as cashier at Bi Mart which "fit my style more," so she stayed. After four years as cashier and back-up receptionist, Mary was asked to be the first woman to join the automotive crew because, she says, "the company was on a campaign to get more women into the departments." The pay was the same, but she accepted because she thought it would be interesting. At first Mary was insecure, but she worked hard "sweating right along with the guys, lifting all the oil and antifreeze." Mary liked it better than cashiering because "the days flew by more quickly," while she "was learning new things." She "found out some things aren't as hard as people make them out to be." She was promoted to auto manager after she agreed to move to another town, and she tells:

My husband thought he would find another cannery job, but, when we got there, there was no goodpaying job for him. I got down on him "maybe the pay isn't very good but at least it is something', but he didn't see it that way. After six months he left. 
With her young daughter, Mary "felt totally alone except for the people she had met in the store." Now in Salen, as auto manager, she is getting restless. She wants "to broaden ay knowledge" and expects to move to another department in the store in the near future. She doesn"t want "to stagnate, to spin my wheels." Even though her organization skills are superior, Mary doesn't think she is aggressive enough to get into top management.

\section{3i11 Jaffe, ane 39}

After working seven years in other retail stores, Jill found out that the pay was better at Bi Mart; so she got herself hired as a cashier, and soon worked as back-up receptionist. After eighteen months, she put in for the position of photo-sound clerk, but she was told they "wanted a man for the job." She didn't get it then, but she persisted and eventually did get it. Her boss, the photo-sound manager, encouraged Jill to join into a "strictly voluntary" management motivation course in the mornings before work; she enjoyed the discussions and came to view herself differently. She says:

I decided if I an going to put in all these hours at work I might as well make something of it all. I told myself I 'can do' it too! 
But Jill became unhappy when her boss left and the company brought someone in from another store to take over the photo-sound department. She knew she could handle the job better than this new person. She threatened "to toss in my papers," and was told to "hold out, and you will get the next opening." Nine months later she became photo-sound manager in Salem.

Recently she lateralled to housewares manager and is finding this new job "an exciting challenge." Jill is ambitious and wants to get into MRF, and she says she and her husband will move. In the meantime, she works hard to "get my support from management and from my other friends at work." The physical work keeps Jill in great shape, and her mind is sharp too; people wouldn't believe she didn't finish high school.

Tom Unruh, age 27

Five years ago Tom was in a supervisory position for another discount retailer. He had trouble relating to subordinates; there were complaints he was too rough with them. He "was asked to step down," but he wouldn"t, so he was forced to quit. Tom was glad to be hired at Bi Mart, he says, because "there is more opportunity"--partially due to the fact that "Bi Mart doesn't hire their managers off the street." 
Tom started as a clerk in the sporting goods department. After two years with Bi Mart, he asked to lateral to another town. After another year, he moved again to become sporting goods manager. Because he wanted to live in the Willamette Valley, he made another lateral move for the opening of the new Salem store. Tom $1 \mathrm{iked}$ working in sporting goods, but he "wanted to try something new." Greg moved him to hardware when an operiing for a department manager came along. Tom"s wife, Maggie, was hired as a cashier in the North Salem store, and now works as a photo-sound clerk.

Tom is interested in a buyer"s position and says, "It is important to know the merchandise well, establish seniority, and be in the right place at the right time" to get such a top level job with the company. Tom says, "It"s hard to set a goal. It could be years." In fact, for the entire chain, there is only one buyer under one merchandiser per department.

Meanwhile, Tom 1 ikes managing a department in the store, and says he has learned that:

Getting along with people is important; dealing with people is the most important thing I do. And I am sure people didn't get promoted because they couldn't get along with their store manager. 


\section{VIEW FROM THE BOTTOM}

Clerks and cashiers do not challenge managerial authority, even though they may experience feelings of relative deprivation. Instead they call in sick---they get away with this because others are available to replace them on short notice. But, mostly these employees work to build and maintain the good opinions of management, dutifully taking orders, and apologizing for mistakes. However, when together among themselves, lower level employees often criticize managers in defense of their own actions; this permitted disrespect isn't usually taken seriously.

Clerks and cashiers spend all of their time on their feet. Clerks are scheduled by, and work under the direction of, their department manager. They make department inventories, stock department shelves with the items for sale, and wait on customers. Cashiers are scheduled by the store managers. They ring up sales on cash registers and sack itews for customers at the front checkstands. In their daily interactions, cashiers and clerks acquire the attitudes and learn the cultural rules appropriate to the Bi Mart scene. 
Sarah Thomas, age 34, and Hazel Schlecht, age 50

Sarah transferred as bookkeeper to the Salem store from the bookkeeper's office in another store. This was not a promotion in pay, but she received a new title---"head bookkeeper." She is married, has a teenage son, and lives on an acreage east of Salem near her in1 aws. Hazel, the assistant bookkeeper, moved to the office from the checkstands because she wanted to get off her feet. Both of these "girls" enjoy schedules which permit them to spend their evenings and weekends at home. They see their incomes as "extra" for themselves and their families, and they are glad they don't have the personal financial difficulties of their co-workers who are sole-supporters. They are satisfied with their positions, and Sarah nods when Hazel says:

There are a lot of people in the store working to get ahead, and they have to be willing to leave this store to do it. I'm not. Managers have to move where the openings are; it would be senseless for me to try to get into management.

Bookkeepers work closely with cashiers. They say, "If one of the girls has a problem, we help her until she gets it. But, if more problems continue, the managers get rid of her." Primarily, their perspective is from a paperwork standpoint; sometimes they will telephone bookkeepers they know in other Bi Mart stores and compare notes to see which store had a bigger day. 
Each quarter---every three months---they inventory the net recaipts of the store, but they try to keep the bookes up to date as they go along to reduce pressures on then at inventory times.

\section{Amber Smithson, age 24}

During her first year with Bi Mart, Amber was confused and unhappy. She couldn't decide whether or not to leave on a fishing boat to Alaska with a "guy" she said wanted to take her with him. Amber was heartily ostracized by her peers at the checkstands for flirting with the male customers and "trying to pick up guys." She was always telling wild stories of her evening escapades. The other girls weren't impressed. Neither were the store managers; two of them wanted to fire her. But Greg talked it over with Amber, giving her one more chance, and, finally, she settled down. Now she is an insider and has good friends among the workers. Though she says "cashiering is a thankless job," it allows her to meet her bills, including payments on her brand new, red sportscar. She gets along with the customers, though she reports "some have a chip on their shoulder and take it out on us." If she continues to prove a good worker, she hopes Greg will move her into a department. 


\section{Dorothy Jones, age 45}

Dorothy was hired to cashier for Grand Dpening. She is attractive with a laughing smile and a clever wit. She sets a high standard as she hovers over the younger pretty girls at the registers. She is "a damn good cashier--probably too good." According to a department manager, "they get somebody like Dorathy on the registers and she may never get off." Like most other cashiers, she liked the jot for awhile but "it gets old, and sometimes I feel grouchy. I don't show it if I can help it." sometimes she does complain, in a joking manner, along with the others about rude customers. She put in for a transfer to the receiving department to get nights and weekends off, but, because of a knee injury, she wasn't able to do the lifting required for that job.

Dorothy is fun-loving. She and her handsome husband attend all the store parties in style. Dorothy went to high school with Greg, and laughs as she tells of finding out he, "of all persons", was to be her store manager. She could not have forseen this.

\section{Marty Moyers, aqe 32}

Marty has found her niche. It's no joke that she wears an "I love my job" button. Many others would 
agree the receptionist has a good job. It is certainly more glamorous than cashiering. Marty is outgoing and sexy, and she enjoys dating some of the salesmen she meets in the store.

She began working as a cashier five years ago in another town and had been promoted to toy clerk. But she didn't like being a clerk, so, when she came to Salem, she asked Greg for the receptionist job, and he gave it to her. She says:

Greg understands this is what I want to do so he lets me do it. I think he is happy with my work and feels anything I do here in the lobby is going to be good. We don't always agree on everything; he throws out his opinion and I throw mine right back, but we compromise.

All day long Marty greets people, checks and sells menberships, presses the button buzzer that opens the gate to let the customers in, and counts them. She answers the incoming telephone calls and pages the appropriate responder over the intercom, "drugs, line 1. please, drugs line 1." She checks parcels for incoming customers and writes exchange or credit slips as required; then she directs persons to the department where a clerk takes care of the details of the transaction. She doesn't "try to second-guess what a clerk is going to do," and says, "that can cause trouble." Finally, Marty has been instructed how to 
handle a bomb threat; laughingly she reads to me, "ask their name, their location, where they are calling from..."

\section{Mark Timms, age 23}

Mark applied for a clerk job for the Salem store opening because he was unthappy cashiering in a grocery store where "it was a lot stricter, like being in the army." In addition to meeting new people, he has learned many new things since coning to Bi Mart, and says, "I"m still learning. It is important to me to learn while I work. That is a reason to work."

As a housewares clerk, Mark expressed surprise that many lady customers expected a female clerk; he told me a young woman working in hardware had similar experiences. When the hardware department manager asked Mark to transfer, to his department, the housewares manager made a fuss because she didn't want to lose Mark. The store managers called him to the office, and "asked me what would I like to do?" Mark decided to try hardware, and says, "I really enjoy it. You have to enjoy the work in retail because the money is not that high." Now Mark waits for a promotion to manage a department of his own. And he definitely makes a point 
to check the bulletin board for news of upcoming events. He likes to go to the parties.

\section{Brian Montgomery, age 20}

Brian started parttime for Bi Mart while he was also working a job in an industrial plant, where he "was paid more, but felt like a machine." He found Bi Mart a better place to work, and was happy to get fulltime work. He has even "gotten a break a lot of people don't get as soon"; he has been put in charge of the toy department on a trial basis until he is with Bi Mart for a year. Then he will be officially evaluated, and if approved, he will be given the title of toy manager.

Brian thinks it is important to ask questions. He e likes learning; he "especially learned a lot at a toy meeting with other Bi Mart toy managers, buyars, and salespeople." Since the meeting Brian has been thinking more about his work. He wants to do a good job. He says he needs to generate more sales in toys before so he can get a clerk to help himg "there is more work in this department than one person can handle, but not enough dollars coming in to support even a parttime clerk". Brian looks up to assistant manager Mike Jackson who is "up front" and "doesn't tell you anything that probably isn't going to be true." Mike helped Brian get 
the toy department ready for Christmas, and Brian says, "I learned a lot from him." Brian was particularly impressed that Mike "set definite goals where he wants to go."

Brian likes the bright atmosphere and the friendly people he meets in the store. He doesn't go to all the parties, and he explains:

for instance, we had a pizza party the other night to celebrate whatever, and after the meal broke up they all went to the tavern. I'm too young, so I can't be included in everything.

In conclusion, one of the difficult things to understand about any system of stratification is why people put up with them. Persons of higher rank in the Bi Mart hierarchy understandably appreciate their greater access to power, prestige, and economic resources. A few persons of lower rank accept their status, but most resent it and wish to move up into higher positions. They, too, want to acquire more privileges and higher pay which can be translated into the socially approved symbols of prestige. A conviction that humans can better themselves is an essential feature of the Bi Mart cultural scene. Getting ahead as a cultural theme will be described in the next chapter. 


\section{CHAPTER $V$}

\section{GETTING AHEAD}

"YOU DON"T HAVE TO HAVE A HIGH SCHOOL EDUCATION"

Managers and clerks alike uninhibitedly declared that a diploma is not essential to job procurement in a Bi Mart store. They report, "You don't have to have a high school education to work here"; nor is formal education a prerequisite to getting ahead and becoming a department manager, a store manager, or even a district manager, buyer, or merchandiser. Knowledge to do the work and be successful at Bi Mart "can't be learned from a book." Instead, informants tell me, "It is common sense work." Informants share "ideas about how to do things" which includes a kind of practical realism, a work ethic, a high regard for honesty and competition, and, finally, a commitment to personal development and learning on-the-job.

Practiical Real ism, Work: Ethic, Honesty and Competition

People come to work at Bi Mart with a core set of working class values essential to the traditional American goal of getting ahead. They come to work in an attempt to face the material facts of life, like it 
or not. They need money for survival. They work to make money to buy food, clothing, cars, and other necessities; and they work "to make a profit" in the retail business. In both respects, Bi Mart employees are practical realists; they are not romantic idealists. They prefer to attend to facts, not speculations; they say they can't afford the latter.

Bi Mart people work for money but they also work because they believe work is meaningful in its own right. They seek an identity and relate to the outside world through their work. Joblessness threatens their self concept. According to one informant."it's your job to provide for yourself" and to another "I wasn't raised to take something for nothing." They don't want to go on welfare. One young woman reported how grateful she was to get work at Bi Mart and "go off the dole" even though the money as starting cashier was not better, especially after paying for her child's babysitter. The reward for her in self respect is evident in her improved posture and appearance, and in her more confident and outgoing behavior.

These people would not be happy dropouts. They have to earn their self respect by carrying out their responsibilities to their employer; in doing so, they produce proof of their own goodness and worth. Their vision of a good life hinges upon upward mobility, e.g., 
informants "want a piece of the action" and "a piece of the cake" and, in general, this is a credo of energy and optimism. They recognize their place within a lower social echelon but they are not completely resigned to the poor life. As exprassed vividly by one informant, "I want to go as far as I can as fast as I can." But, in particular, as children of blue collar wage earners without money, or contacts, or the combination of foresight and discipline to support much formal education, or even knowledge about such opportunities, they are launched on their own with little to fall back on in case of difficulties. Thuse, they conclude that their chances of improving their occupational positions are 1 imited.

Nevertheless, in the business world, there is some opportunity for those who lack formal education; and in the retail business, especially at Bi Mart, individuals may be viewed as having "good potential" if they are willing to work evenings and weekends, eager to learn as much as they can about the business, and demonstrate a commitment to getting ahead. The company is willing "to invest" in this type of employee, and a special kind of giving/getting contract is worked out between them because they need each other. Though wages, work responsibilities, environment, and advancement are the issues which are considered important, this is not a 
union contract; Bi Mart employees don't want to join any 1 abor union.

Members of the Bi Mart subculture beli eve "honesty is the best policy" for dealing with each other, personally, and with customers, impersonally. They like to "come right out and tell it like it is," even in the event of making a friend angry, or losing a particular sale. They deal with people, as well as things, at face value, and they report such point-blank policy pays off. Stealing, even petty theft, is a serious crime at Bi Mart,, and security employees hired by the company remind workers of this fact. Theft by outsiders and by insiders is a big worry to retail managers who watch closely and report instances on special forms. Bi Mart store managers prosecute any shoplifter and fire any employee caught stealing. During my research there was one incident wen a department clerk took some hair grooming cream into the men"s room; he was apprehended, taken up to the office, and fired. Because he was "stupid" to risk losing his job for some "free" stolen good, he didn't get much sympathy from the remaining employees. Another time, a bookkeeper was fired for bringing coupons from home and exchanging them for cash from the daily receipts which she tallied for deposit. In general, handling of store money is minimized; cashiers, bookkeepers, and store managers are the only 
persons who come into direct contact with it. But everybody is concerned about it, and as employees move up in position they intensify this concern. A summary of the who, what, and when of money concerns is charted in TABLE $V$. As indicated, cashiers pay attention to the amounts of sales rung on their registers each day and they compare from one day to another with each other. Department managers know what projections of sales their buyers have determined for their departments and they keep informed of actual sales for comparison by checking the running totals kept by the bookkeepers. Store managers sum department projections to store projections and compare them to total sales; similarly, they must keep track of labor costs. Beginning first quarter (in January) and third quarter (in July) employees team up to take physical inventories, or counting of items by department to determine the dollars tied up in holding items for sale. Book inventories are determined "on paper." by subtracting net receipts from 1 anded sales, at the beginning of the the second quarter (in April) and fourth quarter (in October). Quarterly financial reports by department, and by store, for all the stores in the chain are completed, compiled, copied, and sent out from the main office to department managers and store managers in the chain to compare how they are doing. 


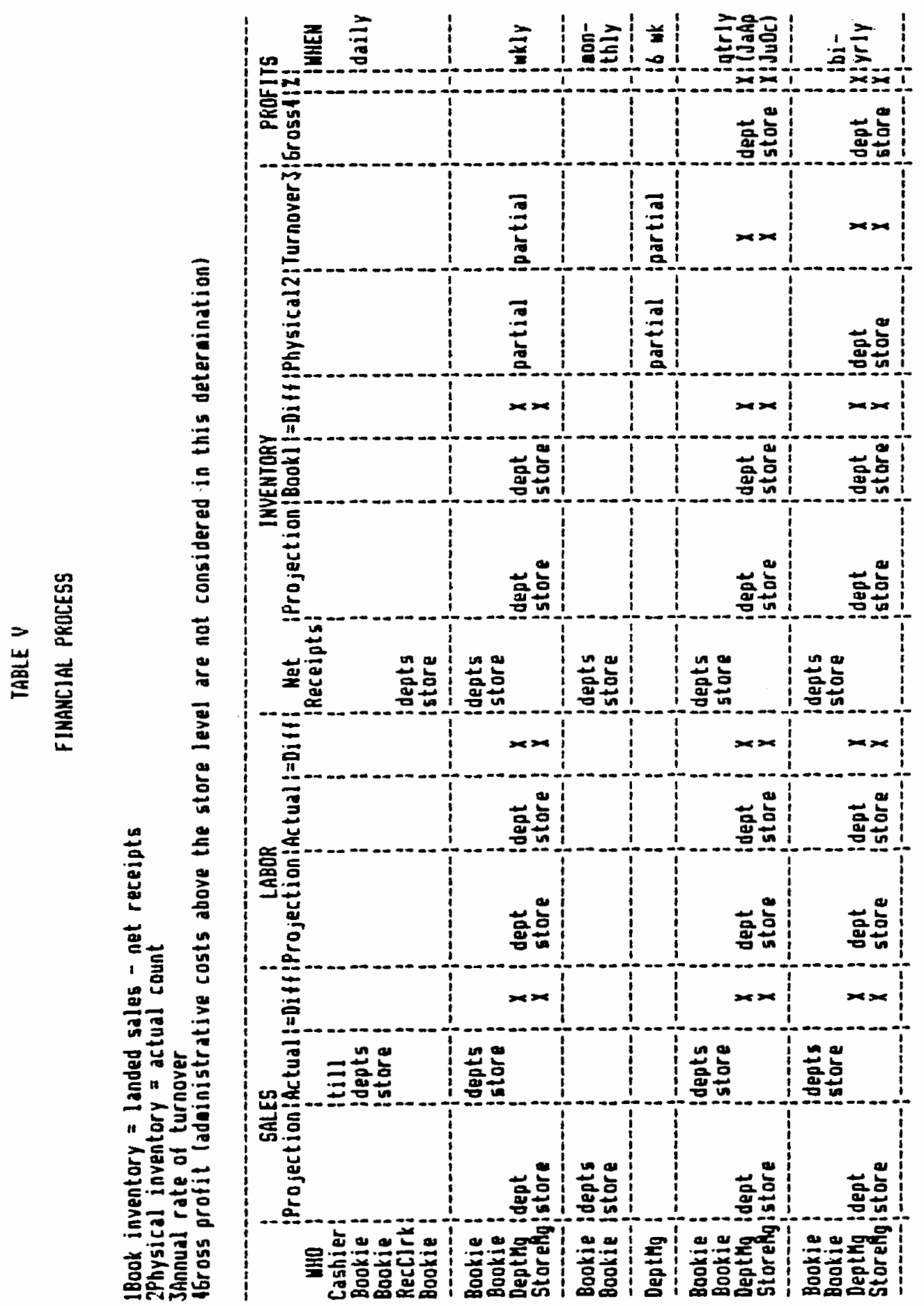


In typical American fashion, informants justify competition as a means to motivation on the grounds that rewards of greater power and prestige are earned through individual effort. Those who make it to to the top should not be deprived of the fruits because they have earned then; and those at the bottom would like to earn them so they try. At Bi Mart, the lesser show deference to the greater and the greater bestow favors to the lesser. So, individuals advance according to performance and favor, the latter depending on the former to some extent.

Formally, once a year, performance of each employee is evaluated by one's immediate superior in writing; department managers write about clerks, and store managers write about department managers and cashiers. And, in person, a store manager holds a private conference with each employee. The written reports are signed and sent to the personnel office at company headquarters where they are kept on file. Less regularly, at the request of their district managers, store managers select an underling or two to evaluate them.

Personality is important for sponsorship; informants talk about "a push" from a store manager who befriends, assists, supports, and advances them. They say this endorsement has been essential to their 
promotions. Shrewd persons dissociate themselves from situations where the odds are against them for sponsorship. Employees are not blind to injustices in this system of uneven exchange of opinions, but most anticipate their "turn" will come. And seniority, in terms of years with the company, is considered in determining who moves ahead.

Within Bi Mart, competition is not "rat race." Individuals don't live out meaningless or disagreeable scripts. Neither is it "cut throat." Persons don"t view each other as enemies. Because relations are face to face, employees prefer to be friendly. Competition is played down among them, as in a family. But most persons know their place and try both to protect and better it. Informally, colleagues are constantly evaluating each other, and individuals continually evaluate themselves in comparison with others.

Among the Bi Mart stores, workers play a competitive game of comparison of sales for fun rand profit). In contrast, Bi Mart people are expected to take other retail competitors very seriously; managers talk about making their store "the best place to shop" and most employees believe "Bi Mart is the best." Thus it becomes a self-fulfilling prophecy. 


\section{Education-On-The-Job}

Informants repeatedly describe their move to Bi Mart as a crucial "step up," usually from blue-collar to white-collar. They were happy to leave behind the impersonal environments and the "drudgery" of factory assembly lines, the "dirty" work in construction, or the "humiliation" of restaurant and tavern work. Such jobs were dead-ends for them. Their parents may have been willing to work "like machines" in exchange for money and a small measure of security, but their children choose instead to be "treated as persons" and "recognized" on the job. And they are willing to expend more energy for less pay if faced with the choice. Self-fulfillment, not self-sacrifice, is their aim. Employees often talk about the "opportunity" at Bi Mart "to meet many people" and "to learn new things."

$$
\text { On-the-job training is a socialization process. }
$$

This face to face exchange of information useful to them in their work is a crucial element in the successful functioning of the Bi Mart system. It involves not only a transfer of ideas about how to accomplish the work at hand but also a succession of attitudes appropriate to the work scene. The experienced ones teach the inexperienced ones. This is all encompassing; examples include a cashier of six months teaching a "new hire," a department manager instructing department clerks, and 
the store manager breaking in a newly promoted thirdperson. This is not a "school of hard knocks." Underlings are taken in tow, not pushed around. At each level the new recruits, who are unconfident (at first), suggestible, and eager to please, do well by learning from the example of the nore practiced employees as teachers. And an atmosphere is created for constant feedback as individuals change roles from trainer to trainee at each step. Bi Mart employees want to, and sometimes do, participate in the decisions that affect their work. And within the established framework, they set their own goals.

Informants brag about the "education" they receive on the job. Unlike the academic world where an individual is on her or his own following a prescribed course and passing exams to meet requirements and receive credentials prior to getting a job, in the Bi Mart world an individual is given an opportunity to demonstrate what she or he "can do" at one level in order to be promoted to the next level where again one is put to the test on the job, and so on up the ladder. Employees learn in small increments; they receive running commentary on how they are doing and recognition for their achievements at each step. They enjoy these small challenges and approach them with determination. The company wants them to succeed, and the workers meet 
those expectations by "doing a good job for them." Ideally, everybody comes out ahead; the ordinary worker produces an extraordinary performance, profits go up, the business expands, more positions open at the top, and more employees rise toward the top. Meanwhile, the company gets good managers who are practical and honest, broadly acquainted with all aspects of the business, and reliably "can do" whatever comes up.

\section{STEPS IN GETTING AHEAD}

Bi Mart employees learn and apply certain patterns of behavior over time. The particular steps in getting ahead which mark passage from one stage of their experience to another were repeatedly described by informants and witnessed by me during the research as indicated in Figure 8. They represent a structure which provides the system with continuity and allows it to function year by year as individuals move up this stairway to success. The structure shows pyramidal solidarity with many employees at the bottom forming the large base and with decreasing numbers reaching higher levels as others settle temporarily or permanently along the way; a few reach the top.

The steps were discovered as employees reiterated their personal histories with Bi Mart. After several interviews it became obvious to me that not only is 


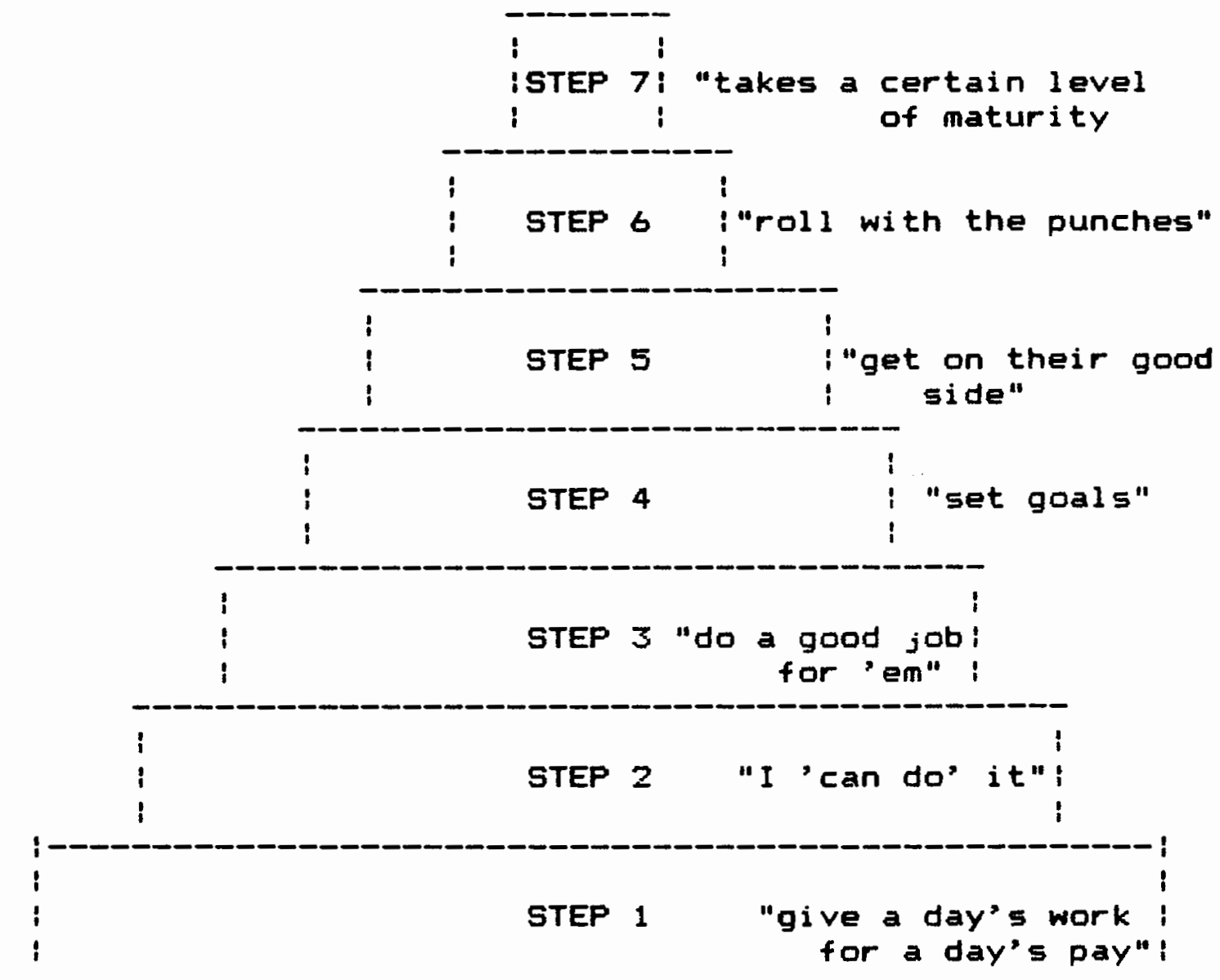

Fiqure 8. Structure of the steps in getting ahead

getting ahead sum and substance to them but also that its form involves a sequence of events which structure hopes, fears, desires, and sometimes disappointments. The positions, ideas, motivations, actions, attitudes, and symbols which employees experience moving up step by step give them their identity. Their self-conceptions are in a large part shaped within the store as they learn from those ahead of them what to expect and what to do to make the most of their experience. In each 
position, employees not only gain knowledge of the details about that stage of the work but also new appreciations of themselves, discovering who they were in the past and who they are becoming. This increasing self-appreciation is valuable to each worker as is, no doubt, the modestly increased salary which accompanies each promotion.

The major steps occur in strict order, so are numbered step 1, step 2, and so on. The particular components which comprise the steps may vary slightly for individuals with different personality traits but usually occur as indicated in Figure 9 . Because they "learned by doing" them, informants became aware of them after the fact.

First step: a new employee merely attempts to "give a day's work for a day's pay" by showing up according to schedule, learning and obeying store rules, and dutifully taking orders given by the bosses. Cashiers learn checkstand procedures and are expected as Bi Mart employees to be friendly and helpful to customers and with each other.

Second step: a worker person looks to see what other employees are doing, compares and says "I can do that too," Cashiers often get bored with checking and in combination with the development of self-confidence ask for additional responsibilities such as relieving in 
the lobby or in the departments. Friendships with other workers blossom as they become increasingly comfortable with each other.

Third step: an employee asks to transfer into a department as a department clerk, who "trucks freight," stocks and displays items on the shelves, and inventories merchandise, in addition to waiting on customers. This person "does a good job for "em." Working with other employees in the department and in the store toward a common goal, clerks also become active participants in store social activities.

Fourth step: a participant "sets goals" for individual personal advancement, e.g., "in (so many) years I want to reach (such and such) position". And again, a department clerk has to let the company know when she or he is ready "to run a department of (my) own." As a department manager, the employee communicates and interacts successfully, while making orders for merchandise, training and delegating work to clerks, and attending meetings with other managers in the store or with department buyers at company headquarters. And department managers who lateral between departments "broaden their knowledge" and learn that "managing is technique."

Fifth step: a self-possessed employee impresses superiors with a commitment and dedication to the 
company, and tries to demonstrate leadership capabilities while performing special tasks. The person becomes friendly with superiors and may socialize with one or more of them in order to "get on their good side." The employee learns it is important to become close with a store manager to act as one's sponsor for entrance into MRP. And if she or he "passes muster" as a candidate, the employee gets a "YES" for promotion to third-person.

Sixth step: the biggest step, an employee waits, and "rollg with the punches." She or he agrees to move anywhere to become third-person in order to move from the floor up to the office where responsibilities increase to the overall store. In addition to helping oversee store operation, third person orders store supplies, manages the beer and wine department, and sometimes tallies timecards to figure the payroll.

Seventh step: a seasoned employee reaches "a certain level of maturity" to set store policy, hire, promote, "cut back," or fire employees. A store manager gives orders in accordance with policies set for all the stores by the district manager. Store managers, most importantly, take responsibility for attempting to neet projections for sales and labor and for reporting store profit/loss. 
Demonstrate ability to accomplish tasks Take orders

Begin to develop appropriate interaction skilis Get along with other eaployees

Be tolerant of complaining customers Help customers

Become familiar with store layout

Be friendly to customers

Saile

Maintain routine

Learn check cashing procedures

Learn cash register procedures

Be willing to "give a day"s work for a day's pay" Dbey rules

Wear a clean smock and nametag

"Punch in" and "out" according to schedule

Show up according to schedule

STEP 1 "GIVE A DAY'S WORK FOR A DAY'S PAY"

Fiqure 9(1). Steps in getting ahead 
Work successfully with others

Be comfortable with other employees

Be liked by other employees

Express desire for new learning experiences

Demonstrate self-confidence

Show interest in department operations

Hustle freight

Relieve in the departments

Demonstrate ability to make decisions

Train others to run the lobby

Direct customers appropriately

Sell gift certificates

Compile "bad checks" list

Sell and transfer Bi Mart memberships

Integrate in-store communication effectively using the intercom

Answer incoming store phone calls

Greet customers

Rel ieve the receptionist in the lobby

Show positive attitude about the store

"Ask" for extra responsibilities

Show positive attitude about self

STEP 2 I "CAN DO" IT

Fiqure 9(2). Steps in getting ahead 
Share in BMEA responsibilities Join BMEA Participate in store social activities "Do a good job for 'em" Cooperate with other department workers Become familiar with display methods Sel 1 to customers Direct customers appropriately Answer customers" questions intel ligently Develop department product knowledge Wait on customers in department Learn "never outs" in department Do price changes

Price department items according to procedures Keep long-distance phone log

Answer department telephone calls Put department merchandise on shelves

Show respect for department manager Take orders from department manager Become a department clerk

Be willing to "hold out" for that next opening in a department

Ask to move into a department

Express desire for more responsibilities

$$
\text { STEP } 3 \text { "DO A GOOD JOB FOR 'EM" }
$$

Figure $9(3)$. Steps in getting ahead 
Use department " $A-Z$ " books

Make department "thefts" reports

Make "defectives" reports

"Figure basic"

Keep inventory controls

Use cal endar

Deal effectively with salespeople

Sign orders

Suggest orders to buyers

Make orders of itens

Demonstrate ability to organize

Learn to delegate authority

Give orders to department clerks

Oversee department operation

Become a department manager

Be willing to move anywhere to get it

Be willing to wait for it

Ask for promotion to dept. manager

STEP 4 "SET GOALS"

Figure 9(4). Steps in getting ahead 
Get a "YES" evaluation

Undergo evaluation by $B i$ Mart team of observers Ask to get into MRF

Get store manager as personal sponsor Help managers with special problems

"Become close" with one store manager

"Drink with the boss" after work, on days off - if you want

"Kiss ass"--if you want

Initiate special projects in the dept.

Demonstrate leadership ability in task accompli shments

Do special assignments for store manager

Help with "closing" the store

Work closely with store managers

Gain experience in several departments

Show interest in all aspects of store operation

STEP 5 "GET ON THEIR GOOD SIDE"

Figure 9(5): Steps in getting ahead 
Share in overseeing store operation

Share in store policy-making

"Open" store occasionally

"Close" store regularly

Arrange for official store parties

Organize drawing of "lucky numbers"

Give orders to dept. managers, clerks and cashiers Collect on "bad checks"

Pick up the store mail

Order store supplies

Become close with other store managers

Become completely familiar with company rule book

Run up/down stairs to answer "customer service"

Move upstairs to the office

Receive keys to the store

Become "third-person"

Be willing to move anywhere to get it

Be willing to wait for opening of "third-person"

STEF 6 "ROLL WITH THE PUNCHES"

Fiqure 9(6): Steps in getting ahead 
Take responsibility for store profit/loss

Take responsibility for meeting store prajections

Carry out store policies as ordered by the district manager

Forestall store problems effectively

Make store decisions with the assistant manager and third-person

Back up assistant manager

Oversee store inventories

Allocate labor according to business and seasonal fluctuations

Fire employees

Promote employees

Lateral emplayees

Approve department schedules

Schedule cashiers

Be willing to move anywhere to get it

Wait for promotion to store manager

Back up third-person

Back up department managers

Act to increase employee productivity

Show high level of maturity in rendering judgements

Discipline employees, if necessary

Handle employee problems

Do payrol 1

OK department work schedules

Suggest and support special projects in the departments

Evaluate employees

Motivate employees

Hire employees

Make security reports

"Proof" store ads

"Open" and "close" store regularly

Become assistant manager

Be willing to move anywhere to get it

wait for opening of "assistant manager"

STEP 7 "TAKES A CERTAIN LEVEL OF MATURITY"

Figure $7(7)$. Steps in getting ahead 
In conclusion, this sequence of steps in getting ahead--of the increasing aspirations, challenges, accomplishments, and maturations of the people in the store---is crucial for the establishment and maintenance of productive work at Bi Mart. The company can pay workers wages which barely support them, especially workers with families of their own, and still brag about low turnover rates because employees believe if they work hard they will be recognized and get ahead. The store as home away-from-home provides the setting; and learning on-the-job provides the opportunity and the know-how. The next chapter offers some insights into factors which underlay the approach to business as described by employees at Bi Mart. 
"HAS ANYBODY TOLD YOU ABOUT "BASIC"?"

THE ORDER OF THINGS

Preeminent in the operation of any retail store is the estimation and interpretation of supply and demand with all its complexities. Manufacturers produce and supply things to retailers who distribute them to consumers who demand them. This economic model of market exchange is inadequate for cultural description because there is more in the exchange itself than just the things exchanged. People make markets work, and at Bi Mart, people are continually sharing ideas, forming value judgements, and exercising decisions, and justifying how they do their business. So that cultural values are brought to bear by following the flow of objects as they are distributed, and observing the ways informants talk about and do their work in the store.

Repeated use of the particular word, "basic," as evidenced in several different contexts within this cultural scene, shed light on the Bi Mart experience. At an unconscious level, the fragmentary uses of this 
key word, "basic", relate a single concept which gives form and contour to their whole way of going at the world. For instance, as an explicit term for purposes of inventory control of what are called "basic items", employees perform according to a mathematical formula called "basic" and define this performance "figuring basic". Implicitly, this "basic" calculation is essential to store and chain operation. In short, informants say, "Basic" is basic to Bi Mart".

Furthermore, organization among whole departments, and within each department, is according to whether the items sold in a department are "basic"; that is, are they necessities or are they luxuries. And more intricately interwoven, is an understanding that lines of merchandise within each department are arranged by features of items from those necessary to "basic" function, or "low" in the line, to those extras "high" in the line. In the following sections, I describe the details of the "basic" way I discovered people at Bi Mart do their business.

\section{Kinds of Items}

Native terms pulled from interviews and observations indicate there are many names for kinds of items sold in a Bi Mart store. Some are listed in Table VI. 
TABLE VI

KINDS OF ITEMS

$\begin{array}{lll}\text { promotionals } & \text { fancy items } & \text { high profit items } \\ \text { big ticket items } & \text { leaders } & \text { low profit items } \\ \text { nickel and dimers } & \text { ad items } & \text { good deals } \\ \text { small items } & \text { feature items } & \text { deal items } \\ \text { storage items } & \text { consumables } & \text { popular items } \\ \text { as-is items } & \text { specialty items } & \text { close outs } \\ \text { back stock } & \text { defectives } & \text { never outs } \\ \text { open stock } & \text { extra items } & \text { nigh priced items } \\ \text { small items } & \text { hardware items } & \text { security items } \\ \text { storage items } & \text { drug items } & \text { self-service items } \\ \text { bulk items } & \text { food items } & \text { luxury times } \\ \text { sale items } & \text { carry overs } & \text { necessities } \\ \text { competitive items } & \text { essentials } & \text { fair trade items } \\ \text { basic items } & \text { display items } & \text { impulse items } \\ \text { top movers } & \text { check list items top stock } \\ \text { overstock } & \text { big seliers } & \text { one-time buys } \\ \text { accessories } & \text { large items } & \text { best sellers } \\ \text { good sellers } & \text { seasonal items } & \text { mark down items } \\ \text { bad sellers } & \text { year round items drawing cards } \\ \text { regular items } & \text { brand items } & \\ \text { staples } & \text { quality items } & \end{array}$

From this list, I was told "basic items" are the most important items; these are "never outs," "essentials," "regul ar items," "year "round items," and "good sellers." These function as "drawing cards" to pull customers into the store and get them coming back again and again.

other items which are not "basic items" include "extras," "special items," "seasonal items," "carry overs," or "promotionals." These are often "deal items" or "one-time buys." 
Arrangements of items on the shelves in the store depend upon this classification of what they are and what they are ngt. Similar items are put together into departments for convenience. As told by an informant:

We don't sell drugs in the hardware department. We do sell oil, oil filters, spark plugs, every thing for the auto in the automotive department.

Within each department, smaller classes of related items are kept together. A store manager says:

We don't want related stuff scattered over a department. The $1 / 2,3 / 8$, and $1 / 4$ inch drilis should be next to each other and in sequence. A customer may come in for the $1 / 2$ inch drill on sale, see the $3 / 8$ and buy it too.

Different items may be arranged to attract attention. As described by an employee:

'Basic items" are stocked on both sides of the gondolas. For contrast, we try to put promotionals on the ends of the gondolas to catch the public's eye.

The merchandisers and buyers for the departments "set" a new store; this means they write the first orders of items and they see the items placed where they see fit. In every Bi Mart store aisle lA is vitamins, $1 B$ is laxatives, $2 A$ is first aid items, $2 B$ is foot products, and so on across the floor. Store managers and department managers adhere to such a schematic (see Appendix B, Figure 11). The managers may be able to put what they want on an end base occasionally, but more often than not they are advised by the buyers to display "deal items" or "ad items" on the ends of the gondolas. 
In fact, when one sees a department clerk stocking a large number of a particular item on an end base, it may be assumed that the item will be going on sale at a special, reduced price soon.

\section{Numbers of Items}

A certain quantity of merchandise is needed to open a new store; this is a "basic" investment in a "basic" inventory, or, to be as explicit as possible, an inventory of "basic items." This is calculated by summing together all the "basic items" for all the departments as determined by the department merchandisers and buyers; it would look something like Table VII.

This "basic"investment (approximately \$1.1 million) is necessary to do business in a Bi Mart store, and a careful selection of items is crucial to getting a good return on the investment. As reported by a store manager, "basically speaking, all Bi Mart stores are the same." This means that any customer can find any "basic item" in the same location in any Bi Mart store. This also means that inventory control in existing stores is used to determine the selection of items to offer in a new store. After a "grand opening", inventory control in the new store provides for adjustment to a particular clientele. 
TABLE VII

BASIC INVESTMENT AND INVENTORY

\begin{tabular}{|c|c|c|c|c|}
\hline ; & & $A-Z$ ITEMS (in units) & \$ & $\mathbf{i}$ \\
\hline i & DEPT 1 & housewares items & $\Phi$ & ; \\
\hline ; & DEPT 2 & photo-sound items & $\$$ & i \\
\hline ; & DEPT 3 & toys & $\$$ & i \\
\hline : & DEPT 4 & sporting goods & $\$$ & i \\
\hline i & DEPT 5 & automotive items & $\$$ & i \\
\hline ; & DEPT 6 & hardware items & $\$$ & ! \\
\hline i & DEPT 7 & drug items & $\Phi$ & $\mathbf{i}$ \\
\hline i & DEPT 8 & beer and wine & $\Phi$ & $i$ \\
\hline$\dot{\xi}$ & DEPT 9 & pharmaceuticals & $\$$ & $\mathbf{i}$ \\
\hline $\mathbf{i}$ & & TOTAL \# of items & $\$$ & ? \\
\hline
\end{tabular}

Inventories are always in process in a $\mathrm{Bi}$ Mart store, as department managers and clerks count items on their shelves at regular intervals and record the unit numbers on stock control sheets sent back and forth to the D.C. buyers (see Appendix B, Figure 15). Each department worker is enculturated with the inventory activity called "figuring basic," and after counting the items applies the "basic" formula which is:

$$
\begin{aligned}
\text { "basic" }= & \text { \# sold } \times 2 \\
& \text { \# of order periods }
\end{aligned}
$$


For example, for item \#2346, Buck knife, model HP, which has been ordered every Wednesday for the last six weeks

$$
\text { "basic" = } \frac{18 \text { sold } \times 2}{6 \text { weeks }}=\frac{36}{--}=6
$$

So the particular Buck knife has a "basic" of 6 . This determines the number to stock as a matter of course, and is prescribed as a base for determining how many knives to order in the future as follows:

$$
\text { "basic" - \# on hand = \# to order }
$$

For example:

$$
6-1=5
$$

So, the department worker knows to order $\mathbf{5}$ Buck knives, model HP, this Wednesday.

This unpretentious inventory control is regularly carried out for all basic items in the store and for some other items. In this way buyers keep track of which items are selling at what rates, and the department managers are able to order items in response to consumer demand for them. Using the "basic" formulas, twice as many items are ordered as are usually selling; this means one item on the shelf for the established customer and another item to attract a new customer. Thus "basic" is the key to a successful Bi Mart enterprise because it allows the company to be particularly sensitive to what shoppers are willing to buy. 
Necessities and Luxuries

According to the store manager, the products for sale in a Bi Mart store are chosen because they "are essential to the normal lifestyle of our customers." And this involves a product mix of basic necessities to attract dollars from their budgets and luxury items to attract their discretionary dollars. I found that employees conceptualize whole departments according to this dichotomy---necessity/luxury---and create distinguishing features that compartmentalize them as indicated in Table VIII.

Thus, employees describe drugs and photo-sound as "two different worlds." The former is a large department and small items are sold; the latter is a small department and large items are sold. Drug employees stack bulk items high so customers serve themselves tearing down displays and devouring the consumable items of the department inch by inch. Photosound employees meet and make friends with customers while providing them with detailed information about the expensive products which are securely displayed in a glass case. 


\section{TABLE VIII}

COMPONENTIAL ANALYSIS OF DRUGS \& PHOTO-SOUND DEPARTMENTS

\begin{tabular}{|c|c|c|c|c|}
\hline DISTINGUISHING FEATU & & NECESSITY & & LUXURY \\
\hline \multirow[t]{2}{*}{ space } & ; & large & $i$ & small \\
\hline & ; & & $i$ & \\
\hline \multirow[t]{2}{*}{ display } & ; & bulk & : & counter \\
\hline & i & & $i$ & \\
\hline merchandising & $i$ & mass & ione & to show/one to go \\
\hline \multirow[t]{2}{*}{ service } & $i$ & self & i & personal \\
\hline & $i$ & & i & \\
\hline security & $i$ & low & $i$ & high \\
\hline size of item & 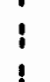 & small & 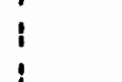 & large \\
\hline product knowledge & ir & -technical & 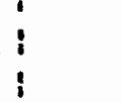 & technical \\
\hline value of item sold & in & =kel \& dime & $i$ & expensive \\
\hline prestige & $i$ & 1 ow & $i$ & high \\
\hline profit & 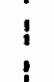 & $10 w$ & 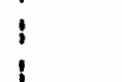 & high \\
\hline turnover & 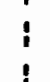 & high & 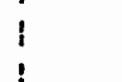 & low \\
\hline \multirow[t]{2}{*}{ competition } & $i$ & high & $i$ & high \\
\hline & 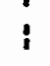 & DRUGS & i & PHOTO-SOUND \\
\hline
\end{tabular}

Housewares is like drugs; there "is an awful lot to keep track of", and employees are always stocking and rearranging merchandise on the shelves trying "to fit it all in" before the next ad breaks. Sporting goods is like photo-sound because shoppers "don't have to have anything from this department" and employees do the "little extras" for customers to get them to come back again to purchase the high profit, luxury items. 
Hardware adheres most strictly to a detailed schematic (See Appendix B, Figure 13 and Figure 14) for display of basic items for customer self service; the department includes a year 'round paint section and a garden section in spring and sumner. In early autumn, toys expands into this area to meet the needs of Christmas shoppers. During the rest of the year, toys is a small department selling craft items, toy gifts, and other luxuries all year.

\section{Lines and Ends}

As a rule, manufacturers organize their products into lines of items of a similar kind; retailers choose particular lines to stock. For example, Bi Mart stocks an Ansco line, a Kodak line, a Vivitar line, and a Minolta line of pocket cameras. These lines are ranked "low line" to "high line"; and within whole lines, features are differentiated and ranked "low end" to "high end."

Organization of lines of pocket cameras in a Bi Mart photo- sound department was charted by the photo manager as indicated in Figure 10, vertically, for whole lines, and, horizontally, from end to end within the 1 ine. 


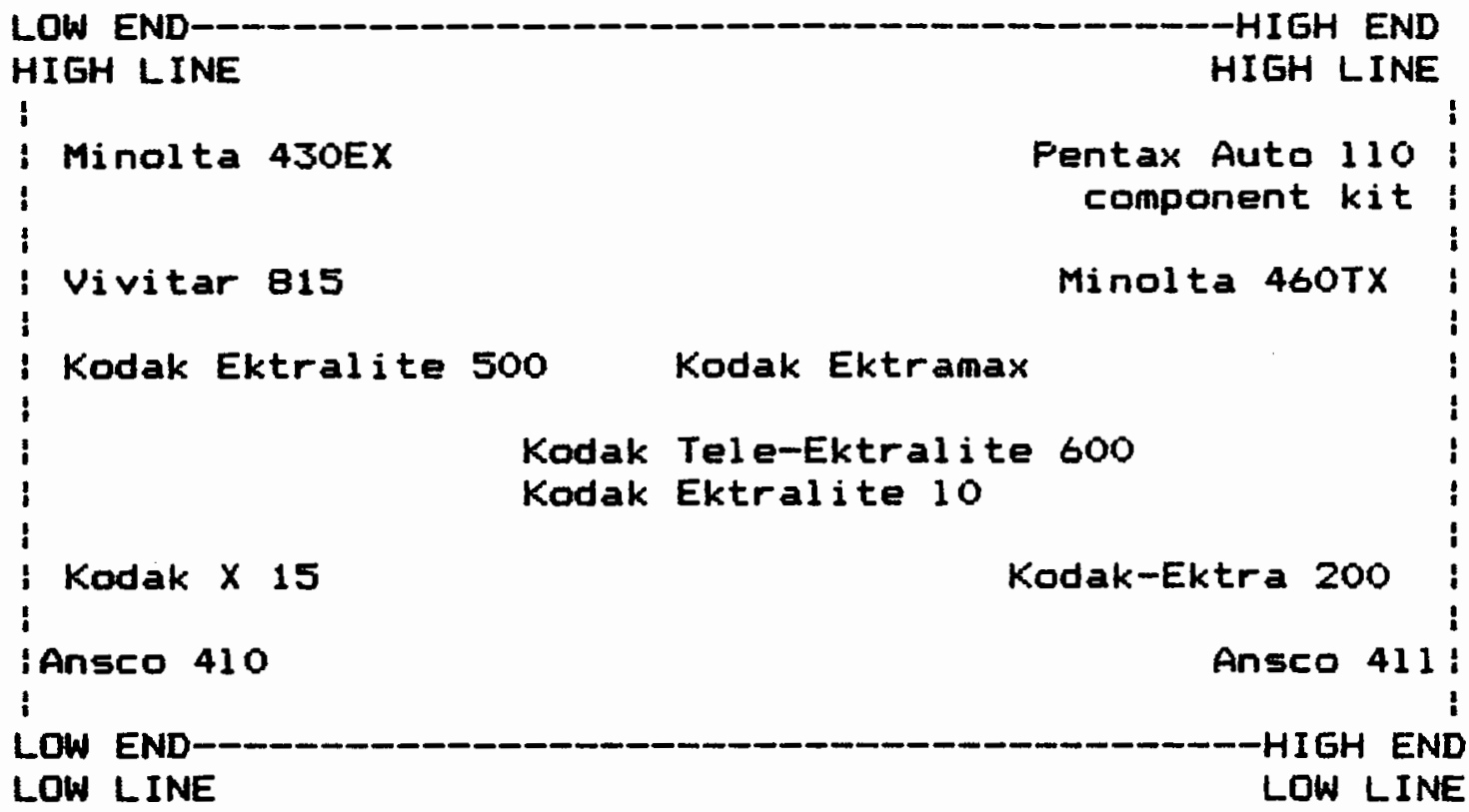

Eigure 10. Analysis of pocket cameras

The features which distinguish the criteria for ordering pocket cameras, or any other item in the store, are sorted in TABLE IX.

In summary, low ends tend to offer only those features of the item which are basic, or necessary, to it's primary function; and high ends offer many extra features which enhance primary function or may be spurious to it, but which increase its value. 
TABLE IX

COMPONENTIAL ANALYSIS OF MINOLTA LINE OF POCKET CAMERAS

\begin{tabular}{ccc}
\hline DISTINGUISHING FEATURE & NECESSITY & LUXURY \\
price & Minolta 430 Ex & Minolta 460TX \\
order of purchase & fow & high \\
quality & lower & last \\
form & package deal & components \\
profit & low & high \\
turnover & high & low \\
prestige & low & high \\
\hline & LOW END & HIGH END
\end{tabular}

"THE BOTTOM LINE"

Looking back at my investigation, I see that there was no other way to explain this culture except in terms of "basic". Whether, in each instance, this notion originated inside or outside this scene, it permeates and gives form to many domains of $\mathrm{Bi}$ Mart experience, and thus can be said to characterize an unconscious cast of the culture as a whole.

Informants make a virtue of necessity. Their "hold down expenses" approach is austere in style and prudent in application. Employees understand it, and it 
appeals to them, because these individuals live their own lives by the same hard and fast rules. They, themselves, represent "the bottom line, or the laborers which support an affluent society. In their personal lives, they struggle at a near subsistence level to make ends meet. At work, they sell many products of the good life, which they cannot afford to buy themselves, to others who can. But they work to "make the most of it" and "get ahead," to raise themselves one step at a time from the low end of the line, so to speak. They work toward a time when they can share some of the luxuries, as well as the necessities, of the good life. 


\title{
CHAPTER SEVEN
}

\author{
CONCLUSION
}

"IT"S COMMON SENSE WORK"

We must, as in all other cases, set the observed facts before us and, after discussing the difficulties, go on to prove, if possible, the truth of all the common opinions about these affections of the mind, or failing this, of the greater number and and the most authoritative; for if we both refute the objections and leave the common opinions undisturbed, we shall have proved the case sufficiently (Aristotle).

Common sense is a dimension of culture not usually conceived as a realm for description and study, but is thought to comprise one large realm of the given or undeniable, or realities so apparent as to force themselves upon any mind unclouded to receive them. Yet this is clearly not so (Geertz 1975). At Bi Mart, common sense refers to particular ideas about "how things really are" which members in this culture catch on to and choose to embrace.

As stated by an informant, "Common sense is what Bi Mart is all about!" Members refer to a special body of shared knowledge which seems to make sense to them, as a general rule, because as their resource for understanding, explanation, decision-making, and problem- 
solving it works for them. Common sense as they perceive it is useful for getting things done; and persons who have common sense are useful in a cultural scene in which usefulness is highly valued. In a nutshell, shared convictions assume a form of utilitarianism that seem to reasonably claim the endorsement of common sense.

What informants refer to as common sense is difficult to characterize but may be extracted fron native terms and everyday expressions. It's in the name---"Bi Mart." It is so straightforward---a place to buy, a market---and this denotes precisely what it is, nothing more or less. It is economical, thus reflecting their frugal approach to business in particular, and to life in general. And clearly the name is practical; it is so simple for customers to write on their checks---a matter which bears directly on their immediate, material interests.

Just as members of this subculture adopt a "no frills" approach to business, they employ a "no frills" application of language. When they assert "'basic' is basic to Bi Mart" it sounds like doublespeak but it's not; their meaning is literal---e.g., the particular calculation of the number of items to stock and order underlies their whole operation as described in CHAPTER VI. Primarily, their speech functions to connect 
action to its sense. For instance, employees carefully perform this inventory control of basic items day in and day out on the job. Then to enable them to talk with others about what they are doing they become aware of the term which has come to exist to describe this primary activity. "Basic" is part of what everyone at Bi Mart knows. This knowledge is not academic; they don't discover the term, then seek to learn its definition. In reverse, first employees "do basic," then they talk about doing it.

\section{"Two Different worlds"}

It is through particular instances that other premises of common sense may be witnessed, identified and connected to the rest of culture to tell what life is like at Bi Mart. Employees recognize and explain "it's two different worlds" in drugs and photo-sound: one of necessity, another of luxury. Implicitly this sense of relations is an ultimate source of order at $\mathrm{Bi}$ Mart. In their personal lives, these persons have been compelled to deal directly with the former most of the time; in sharp contrast their perception of the latter is indirect and implied. So it is not surprising that a fidelity to a kind of habitual minimalism permeates into their work lives. Several informants reported that "you don't have to have a high school education to work at Bi Mart"; instead they touted experience. Experience is an 
unavoidable necessity; formal education is a luxury open only to those who can and do choose to pursue it. Informants believe experience reports the true account of knowledge of the world. It is important for them to be able to grasp the actualities of experience on-the-job and come to sensible conclusions on the basis of them. Apprehensions of sense data may be matters of fact, but assessments of experience are interpretations, which are based on the unspoken, underlying themes from which comanon sense, as they define it, takes its authority.

"How Do You Teach Common Sense?"

One evening a store manager who was frustrated by a bungling employee asked me, "How do you teach common sense?" I would have been flattered by his implication that I possessed it (and thus he considered me an insider) except that the important (to him) implication was the impossibility of teaching it. It didn't occur to him to teach it because common sense impressions, and the judgements to which they are subjected, are glossed over, as in myth, so that they appear either as inherent assumptions or foregone conclusions.

Nevertheless, common sense is not untutored but instead is taught everyday at Bi Mart as knowledge expressed in situational terms, rather than in terms of 
abstracts, is transmitted from worker to worker in an informal fashion. Experienced employees act as role models for new hires who imitate them and, step by step, develop a feel for what's going on. Experience teaches via slogans, success stories, and integrating myths which convey the guiding values of the subculture. Acceptable attitudes are rewarded and increased. Undesirable idiosyncrasies are worn down and drop off during this shaping process. While workers learn the necessary skills to get things done, they also develop the confidence to try to learn more and more in the pursuit of the institutionalized goals. This structure of the stuff of learning as outlined in CHAPTER $V$ provides the context for commitment to belief habits which through familiarity take on an appearance of obviousness. In this way, common sense offers a built-in way of thinking which appears as a necessary authority for matters of fact. These premises cannot be proved on grounds that surpass them in clarity, but, nevertheless, they are agreed upon without serious misgiving about their value and/or validity.

But there are differences between education at Bi Mart and academic education which informants do not see (or choose to see) because the latter is outside the realm of their experience. Knowledge at Bi Mart is "know how," or knowledge by direct acquaintance, and 
involves problem solving. Wisdom, at Bi Mart, is "the maturity" to stay "on top" of things. In this sense, what they refer to as common sense is the antithesis of knowledge which arises from questions and the attempts to answer them, which leads to more and more questions and answers, and to the wisdom that that "the more one knows, the more one knows one doesn't know."

People learn different lessons and draw different conclusions from experience depending on what they have learned. And the more educated the individuals, in $\underline{a} \underline{1} \underline{1}$ kinds of knowledge, the better they are able to recognize the most fitting contexts of the facts. In schools and laboratories, students search for ideas and second- or third- or-nth-hand explanations and appreciations to "build into" their first-hand observations of facts and data. For them, common sense may be a necessary (and suspect) starting point; but at Bi Mart it is more a be-all and end-all.

\section{"Willing to Move"}

For instance, so that Greg would not turn down a transfer he "was called and told "the facts of life"--the company wanted (him) to move to Ashland." As stated by another informant, "It just wouldn't make sense for someone to go into management if they weren't willing to move." The proper attitude was expressed by an informant waiting for a promotion, who said, "I will 
move anywherere to get it."

Moving, as a necessity, is imposed upon common sense, not inherent to it. And it is as part of this constructed common sense that a preoccupation with physical movement takes on its meaning and force within this cultural scene. Employees move around from town to town to move up the corporate ladder. They don't want to "spin their wheels" in the same place and, instead, are motivated to "go as far as (they) can as fast as they can," and this they do with a "push" from a store manager. Meanwhile, they continually move things into the store, onto the floor, up onto the shelves so customers may move them out the door. Yet, mentally, the same persons adhere to a world view which allows them to go nowhere in their minds except where they have already been.

\section{"It's Just That It's Just That Way"}

To focus attention on what is closest to the surface, however useful, may be a denial of the the complexities of things and/or an escape from their inconsistencies. Complexities may be avoided because a focus on what"s common, in the vernacular "ideas that coincide," doesn't require comprehensive appraisal of subjects but instead regenerates metaphorical expressions to remind people of what they already know. 
Inconsistencies may be evaded because the content isn't categorized, nor the form formalized; appeals to common sense are essentially reactive; its content is declared in attacks upon assertions which practical good sense in everyday affairs would oppose. So that common sense is best characterized by a mish mash of vague notions; thus, as common denominators, these ideas are flexible enough for dealing with "whatever come up next."

Participants in this cultural scene can at least secure the neutrality of common sense when they can't have its assistance; therefore, common sense reasoning may be commensurate with any cherished hopes or desires, and it may be designed not to disappoint or confuse but to elicit and defend the "truth" of common persuasions. In such instances, common sense may be rationalization, not rationalism; and this might be reason for its appeal in complex tines.

Without a doubt, there is a kind of security at $\mathrm{Bi}$ Mart in the close adherence to the cluster of customary beliefs simply derived directly from knowledge through experience. The outer world need not be regarded except as it may help or hinder what is going on within the cultural circle. Their kind of training, in some respects, 1 imits their scope of creativity, and, on rare occasions, members, against their grain, express frustration with the shallowness of their experience and 
the naivete of their world view. To shrug the shoulders and say "it's just that it"s just that way" facilitates getting on with the work at hand but seems, at times, inadequate as explanation for something not immediately self-evident to them.

Sometimes employees express the desire to free themselves from the prejudices of common sense; they say they feel a need to seek knowledge, for knowledge's sake, but instead they continue to direct their energies to the more personal problems of the here and now. Informants tell how they scaled down their dreams of owning their own businesses or of becoming chemical engineers or psychologists to work within what they describe as a more realistic sphere of possibilities.

\section{"Fits My Lifestyle"}

While participating in the Bi Mart cultural scene, employees build up a repertoire of rough-cast wisdoms, practices, and beliefs which allow them to cope effectively in an everyday way. They acquire visions of improving their lots through company training and development of their potentials. And many do find a route to fulfillment with Bi Mart. They come to take pride in their achievements and to enjoy an image of themselves as a community, or "family," in which relations are immediate, concrete, congenial, supportive, and loyal. Parties and ritual celebrations 
of holidays, birthdays, marriages, promotions, store anniversaries, and Grand Qpenings draw them even closer in their work and provide entertainment and relief from the banality of their ordinary lives. So that life at Bi Mart, while satisfying demands for individual expression and fulfillment, is also very much a social activity with social implications.

In essence, this potpourri of common sense notions characterizes the Bi Mart cultural scene; sometimes they are architected into formal doctrines, sometimes not. To me, as anthropologist they outline an ethnography of cultural values; to members of the Bi Mart subculture they represent what anyone with common sense knows. Their redundancy as expressed in interviews, anecdotes, even jokes, reveals their closeness to the hearts of the developed traditions of thought and sensibility which members use to shape their 1 ives as they participate in this cultural scene.

\section{EP ILOGUE}

For Bi Mart culture to continue as members describe it, they must maintain faith in the reliability of these sentiments. Whether this is possible is a question posed in the face of certain threats. The Bi Mart company has sold out to the Pay' $n$ Save corporation to get money for Bi Mart expansion. Bi Mart continues 
to function out of its own offices in Eugene, Oregon but under the auspices of the Pay 'n Save offices in Seattle, Washington. (Pay 'n Save also owns LaMonts, Ernst, Malmo, Schucks, Yardbirds and other small chains.) In America, successful companies get more successful, and the success of the Bi Mart system is largely dependent on a continual supply of fresh openings at the top. These positions at the top fill first, and employees who come later have to wait longer. As their individual climbs up the ladder are slowed, informants begin to question whether it will be worth the wait. Ten years ago an eager employee could become one of the store managers in five years; today it is taking ten years to reach such position.

"Getting ahead" is a prime motivater of Bi Mart workers. If a large gulf forms between expectations and the obtaining of higher positions, malaise may set in and employee productivity drop off. Serious stagnation has been temporarily avoided by raising standards and weeding out less desirable persons to create openings--as evidenced by several firings of managers and, more importantly, by the creation of the Management Review Program, an idea borrowed from Pay'n Save. This new manager selection program puts one more step in the process--a kind of mezzanine between downstairs and 
upstairs where candidates "hold out" awaiting a turn to move up.

At the same time, Bi Mart people emphasize a need to maintain Bi Mart as a unit distinct from Pay 'n Save. Their culture is unique; fictive kinship is their creation as are the other culturally developed traditions and sensibilities which give meaning to their 1ives. Persons in the Bi Mart store produce something valuable because they feel valuable, and they are made responsible because they are given responsibility. Historically store autonomy has provided a comfortable context for personal contribution and commitment in support of the common purpose. Now employees fear rigidity will come with size and demeaning rules will be imposed from above. A culture cannot be forced upon a people. It is not so much articulation of what employees should be doing as it is the creation of a compeling moral necessity to do what is best for the company because it is best for themselves. Thus, their work makes sense to them, and good will permeates the whole of it. For Bi Mart to survive, its people must continue to believe in it and make it work. It is up to them.

There is no conclusion. What has concluded that we might conclude in regard to it? There are no fortunes to be told and there is no advice to be given. Farewell (Willian James). 
REFERENCES

Berkeley, (Bishop) George

1713, Three Dialogues Between Hylas and Fhilonius,

Bohannon, Paul

1980, "You can't do Nothing," American Anthropologist 80: $508-524$

Clinton, C.A.

1977, "The Uses of Cultural Ecology in Urban Dccupational Group," Anthropology Quarterly 50(1) 39-44

Crane, Julia G. and Michael Angrosino

1974, Field Froiects in Anthropol ogy, General Learning Press, New Jersey

Crick, Malcolm

1982, "Anthropology and Knowledge," Annual Fieview of Anthropology 11 : 287-313

Dow, James

1975, "On the muddled concept of corporation in anthropology," American Anthropologist 75: 904908

Eddy, Elizabeth and William Fartridge

1978, Apelied Anthropology in America, Columbia University Press, New York

Edgerton, Robert and L.L. Langness

1974, Methods and Styles in the Study of Culture. Chandler and Sharp, Los Angeles

Gamst, Fred

1976, Ideas of Culture: Sources and Uses, Holt, Rinehart and Winston, New York 
Geertz, Clifford

1976, "From the Native"s Point of View: on the nature of anthropological understanding," Meaning and Anthropolgy, editor K. Basso, 221-237

1975 "Common Sense as a Cultural System," Antioch Feview 33: $5-26$

1973 Intergretatign of Culture, Basic Book:s, New York:

Goffman, Erving

1959, The Fresentation of Self in Everyday Life, Doubleday Anchor, New York

Goodenough, Ward

1956, "Componential analysis and the study of meaning," Langulage, 32: 195-206

Hal 1, Edward

1966, The Hidden Dimension, Doubleday Anchor, New York

Hanson, Norwood Russel 1

1958, Fattegrg of Discovery, Cambridge University Fress, New York

Hines, Virginia

1977, "The basic paradigm of a future socio-cultural system," World Issules, I I (2) 19-22

Holzberg, Carol $S$ and Maureen Giovanni

1981, "Anthropology and Industry: reappraisal and new directions," Annual Review of Anthrogology 10: 317-359

Lof 1 and, John

1976, Doing Social Life, Wiley, New York:

Mal inowski, Bronislaw

1922, Argonauts of the Western Facific, Dutton, New York

Marcus, George and Dick. Cushman

1982, "Ethnographies as Texts," Annulal Fieview of Anthropology 11: 25-69 
Pelto, Perttii i and Gretl Pelto

1970, Anthronological Research: the Structure of Inguiry, Cambridge University Fress, New York

Richardson, F L W

1979, "Social interaction and productivity," The Uses of Anthropology, editor W Goldschmidt, $79-99$

Russel 1, Bertrand

1912, The Froblems of Fhilosophy, Oxford University Press, London

Spindler, George, editor

1980, Being an Anthropologist, Holt, Finehart and Winston, New York

Spiro, Mel

1965, Context and Meaning in Cultural Anthropology: The Free Press, New York

Spradley, James

1980, Farticipant Observation, Holt, Finehart and Winston, New York

1979, The Ethnographic Interview, Holt, Rinehart and Winston, New York

1972, "An ethnographic approach to the study of organization," Complex Organizations and their Environments, Brinkerhoff and Kunz, editors, W C Brown, 94-105

1971, "Cultural deprivation and cultural inundation," Southwestern Canada Journal of Anthropology 2: 65-82

1970, You Owe Yourself a Drunk: An Ethnography of Urban Nomads, Little, Brown, Eoston

Spradley, James and Brenda Mann 1975, The Cocktail Waitress: Woman's Work in a Man's world, Wiley, New York

Spradley, James and David McCurdy 1975. Anthrogology: The Cultural Perspective. Wiley, New York 
1971, The Cultural Experience. Science Research Associates, Chicago

1971, Conformity and Conflicta Fieadings in Culturus Anthropology, Little, Brown, Boston

Spradley, James and Michael Rynkiewich

1976, Ethics of Anthropology: Dilemmas in Fieldwork. Wiley, New York 
APPENDIX A

LIST OF NATIVE TERMS

"as is" items

back stock

"basic" stock contral

"basic" formula

best sellers

bill of 1 anding

blue line

brand items merchandise not in perfect condition, shopworn, slightly damaged; and offered to customer "as is" at reduced price.

merchandise kept under counter or in stockroom, which is to be used to replace counter stock as it is sold; the one to go in "one to show, one to go".

type of stock control designed to keep proper quantity of staple goods on hand.

total number ordered divided by the number of order periods times 2 (sometimes $11 / 2$ for certain categories of items).

items that sell in greatest volume.

written description of goods being shipped; also a contract between shipper and carrier for specifying routes, delivery terms and other information pertaining to shipping.

blueprint of ad from newspaper to be "proofed" before ad comes out in the paper.

merchandise under trademark of a manufacturer; national brands sold throughout the country. 
bulk stack

buyer

carry over

cash discounts

chainstore

checklist

checkstand

(or check out)

close-outs

code dating stacks of merchandise without shelving, like bags of fertilizer in hardware, cases of oil in automotive, or paper goods in drugs.

a member of the home office staff who selects new items to be sold in the stores; a buyer also lays out a department, sets up ads and ad programs.

unsold seasonal merchandise related to a specific season or holiday, e.g., Christmas.

reduction in price allowed for prompt payment of amount on invoice. This can be ex pressed in many ways eg. 2\% Net 10 days (to be paid ten days from the date of invoice in order to get a 2\% discount). The terms are written on F.O. exactly as stated on stock control cards.

store organization of two or more stores centrally owned and operated and usually carrying similar merchandise.

"never outs" or "must" items which a store should have "on hand" at all times.

counter section at exit of self-service store at which cash registers are located.

discontinued merchanise or seasonal items marked down for quick sale.

code on price stickers that shows month and year items arrived into store. 


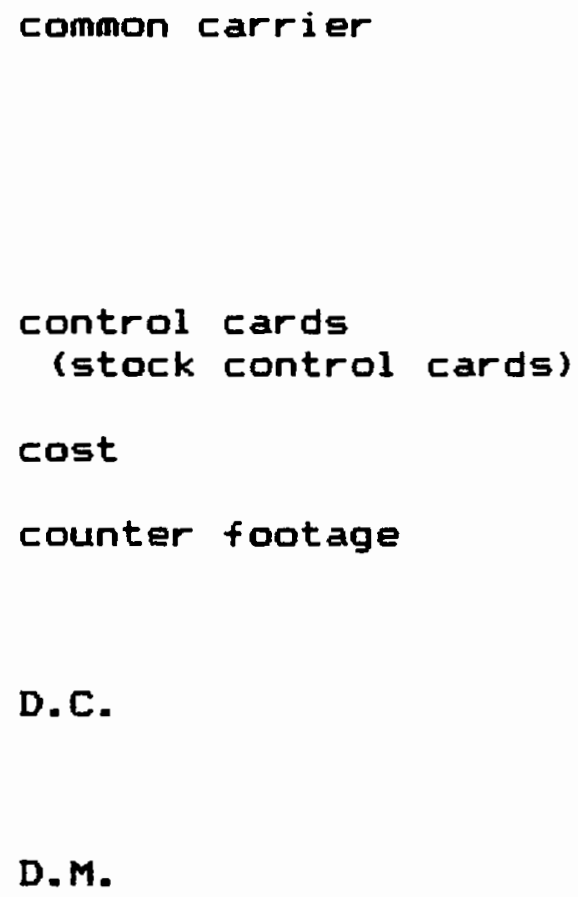

any transporting company (or individual) carrying persons, property, or messages for pay. In retailing, the term refers to railroads, trucking ca.s. postoffice, or other express.

inventory control sheets (see Appendix B, Figure 15)

vendor's price to retailer

square: counter top area in feet.

lineal: length of counters

distribution center, home offices and warehouse in Eugene

district manager, the person who oversees all the stores in a particular district. This is a step above store manager, a step above the store level.

the end of a gondola, which faces front and back, where promotionals and ad items are usually displayed.

an invoice from a common carrier showing the quantity of merchandise being delivered, weight of shipment, cost of delivery, from whom, with an identification \#

freight on board, this is the point where the buying company is responsible for the items. 
floor

gondola

gross margin

gross profit

i mpul se i tems

independent store

inventory

invoice

l anded cost

lay out the first level, first "floor" areas of the store to which customers have access, and including the lobby, the departments, and the check stands. The floor may be observed from the upstairs office window.

island type of self-service counter with tiers of shelves running their full length.

difference between net sales and merchandise costs.

in percentage form, selling price minus cost price divi ded by selling price.

items generally bought by customer on the spur of the moment.

single store unaffiliated with other retailing outfits.

stock on hand; physical inven tory is determined by actual count of units of stock. book inventory (or paper inventory) is doll ar value of inventory as recorded by bookkeepers in accounting.

itemized list sent from seller to buyer giving \#, description and cost of items.

cost of merchanidise plus cost of transportation

schematic, allotment of dis play space to each kind of item, usually apportioned to rates of sales (See Appendix B). 
leased department

line

labby

mark up

merchandi ser

net profit

net receipts

(net sales)

open to buy

P.o.

pin ticket

projections

promotions

(promotionals) merchandise or service department rented to outside management.

an assortment of merchandise (by price, color, style, etc.) within a major classification of merchandise.

store front entrance, where receptionist sits and checks and sells memberships.

difference between cost and retail selling price of item; to get percentage mark up divide markup by cost price.

head buyer for a department

gross margin less expense gross sales minus returns and al lowances

amount of money available for ordering merchandise, usually with reference to a particular department.

purchase order, a form for writing the agreement between buyer and seller

small price ticket attached to merchandise by wire staple or pin.

predicted amount of sales for each quarter by department and by store; goals to be met which are usually a challenge.

special selling efforts to launch new items, clear old stock, meet competition, or increase sales. 


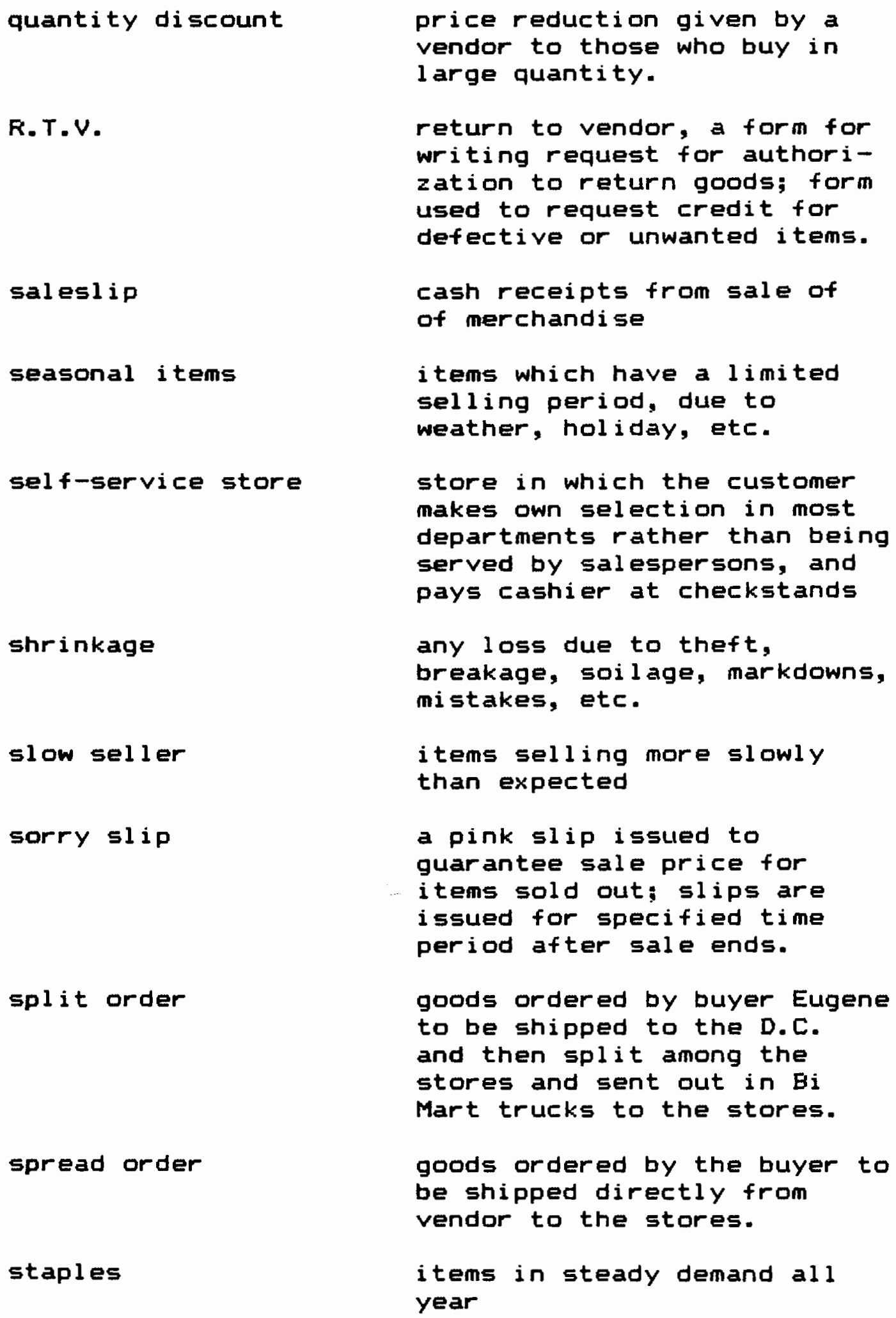
year

price reduction given by a vendor to those who buy in large quantity.

return to vendor, a form for writing request for authorization to return goods; form used to request credit for defective or unwanted items.

cash receipts from sale of of merchandise

items which have a limited selling period, due to weather, holiday, etc.

store in which the customer makes own selection in most departments rather than being served by salespersons, and pays cashier at checkstands

any loss due to theft, breakage, soilage, markdowns, mistakes, etc.

items selling more slowly than expected

a pink slip issued to guarantee sale price for items sold out: slips are issued for specified time period after sale ends.

goods ordered by buyer Eugene to be shipped to the D.C. and then split among the stores and sent out in $\mathrm{Bi}$ Mart trucks to the stores.

goods ordered by the buyer to be shipped directly from vendor to the stores. 


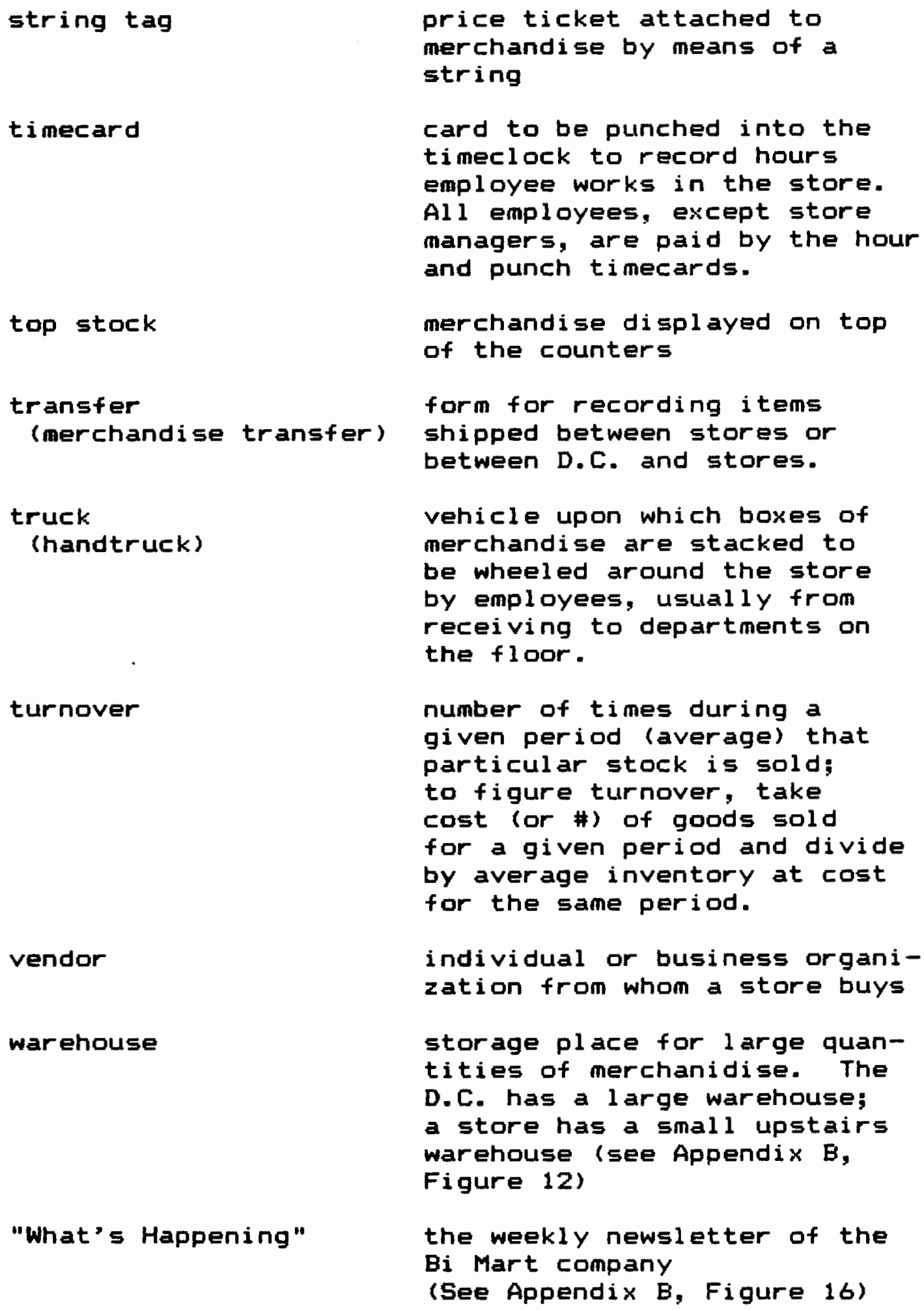


whol esal er

business organization that buys large assortments of items from different manufac turers and sells in smaller lots to retailers. 
APPENDIX $\mathrm{B}$

ADDITIONAL ILLUSTRATIVE MATERIALS

Fiqure 12. Map of upstairs warehouse

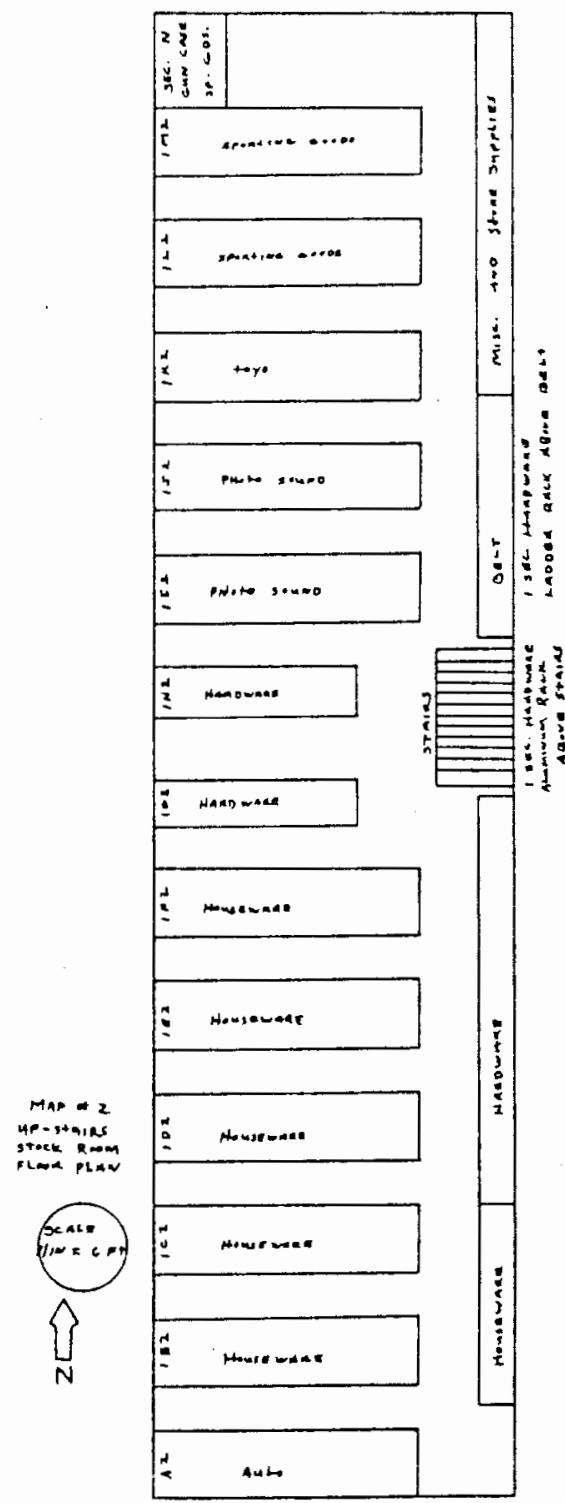


Fiqure 14. Detailed schematic of four-foot section

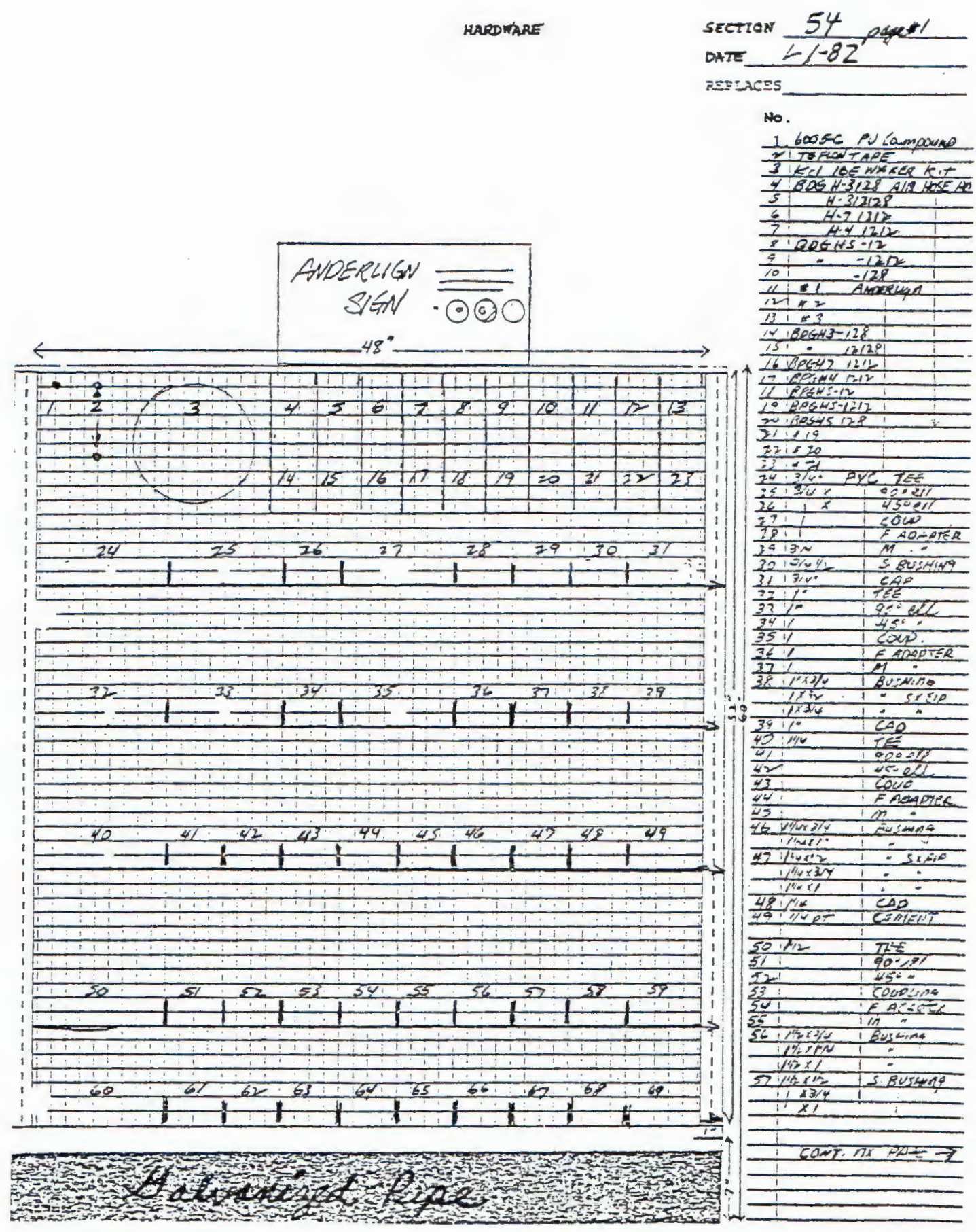




\section{Fiqure 15. Stock contral card}

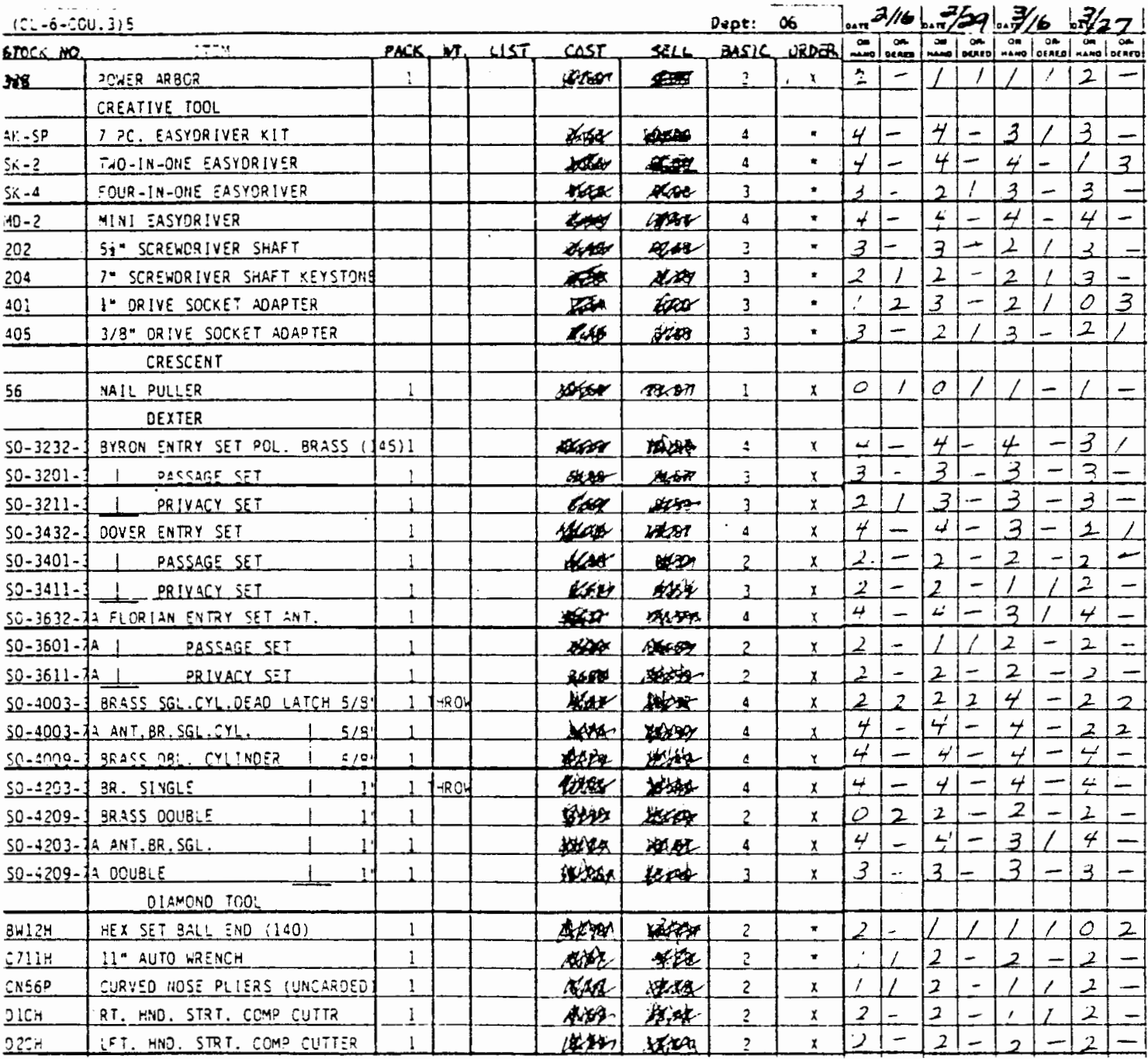




\section{Fiqure 16. "What"s Happening"}

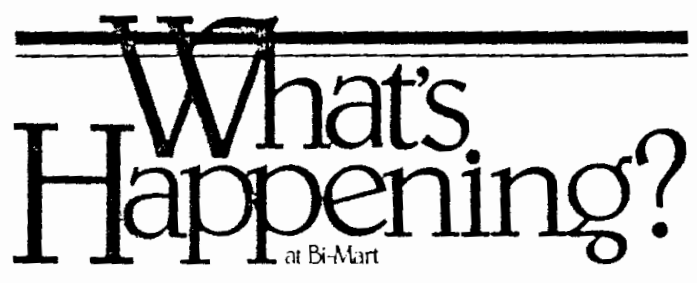

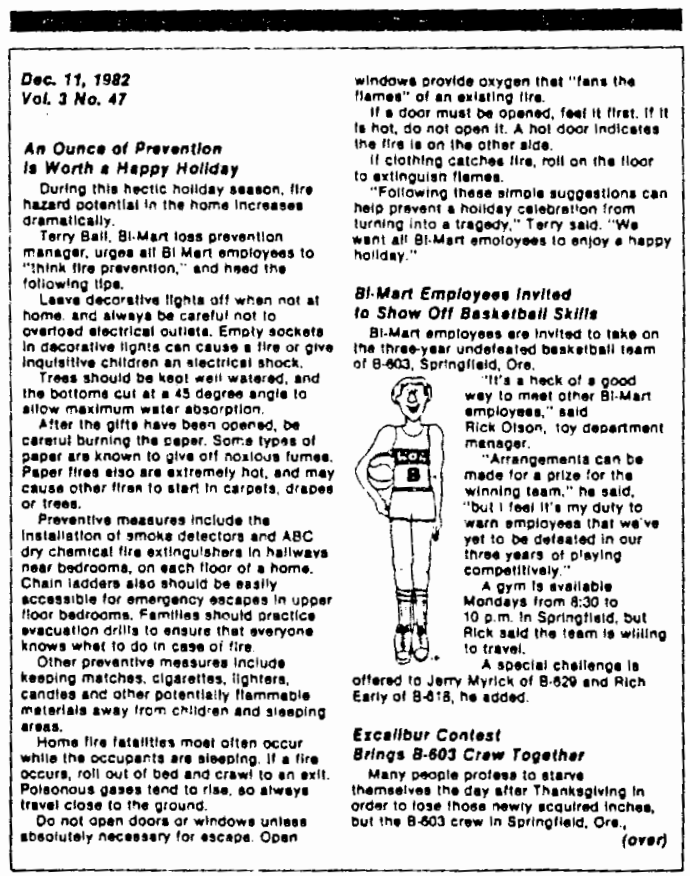

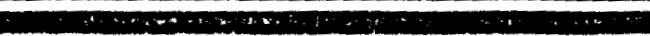

( )

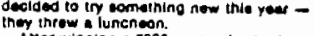
Atrer winning 15000 sath prize in the

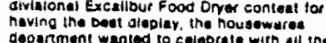

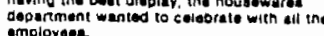

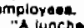

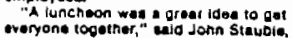
mantagor.

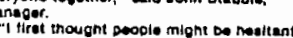

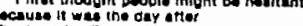

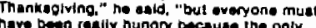

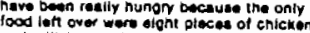
and ittrie aread and iolia

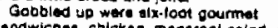

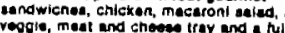
inaticinge.

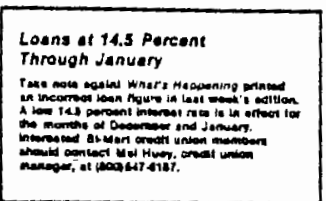

Triple Thenk:

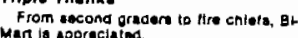

Man is aporcialiod

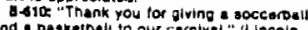
Etomoniary's ancons orede class, Grante IPasa Oreit

Jonn Ford gart: "Ho is atways

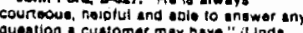
Greplowati, soringtiold, Cre.t

9-806:" "Your gitt al gmake Soticion

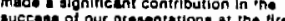

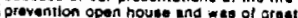
reasonstbility to make ines community a

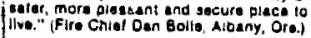

Servies Hanored

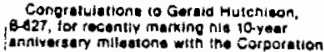

Psomolitons Announced

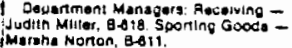

Trenspers Hoted

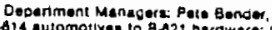
Solby, asil sporing ic B-B11 automsthea Stoch Droeks 32

The dealign of the Whirs Hapoening

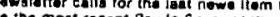

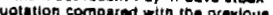
cenk's and the prextous yeeri guotes

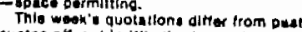
the bid of 3218 quoted foe 0 ac

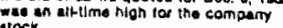

Aerales: How thas's A Drees Cade What you say and what you moan often

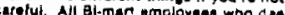

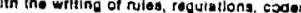
ormetroe for that mettel snould take

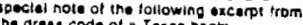

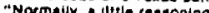

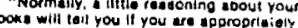
drasece. When in socot coout your

Gat Those Cameres cllcking Thanka to Esther Pomesmo. Alck Oisan John Slovole, Hel Huer and Tern Sal to Heposenting

11 you heve any newe of inroreas to crier

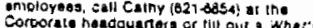
Habpening tho ohat ond sand krough company mult.

Just a remincel - the holiday aosson

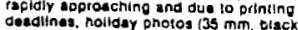

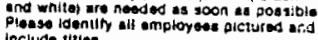

Pey'in Sare stock

32 is (12-09-32) $30.0(11.30-82)$ 